\title{
Titanium, Vanadium and Chromium Valences in Silicates of Ungrouped Achondrite NWA 7325 and Ureilite Y-791538 Record Highly-Reduced Origins
}

\author{
S. R. Sutton ${ }^{1,2, *}$, C.A. Goodrich ${ }^{3,4}$, and S. Wirick ${ }^{2}$ \\ ${ }^{1}$ Dept. of Geophysical Sciences and ${ }^{2}$ Center for Advanced Radiation Sources, \\ University of Chicago, Chicago, IL 60637 USA \\ ${ }^{3}$ Planetary Science Institute, 1700 E. Ft. Lowell, Tucson, AZ 85719 USA \\ ${ }^{4}$ Lunar and Planetary Institute, 3600 Bay Area Blvd., Houston TX 77058 \\ * Corresponding author (630-252-0426, sutton@ @ars.uchicago.edu)
}

Submitted to

Geochimica et Cosmochimica Acta

May 2016

Revised November 2016

Second revision January 2017 


\begin{abstract}
Titanium, Cr, and V valences were determined by applying micro-X-ray Absorption Near Edge Structure (micro-XANES) spectroscopy methods to individual grains of olivine and pyroxene in the ungrouped achondrite NWA 7325 and ureilite Y-791538, as well as to plagioclase in NWA 7325. The advantages of applying multiple, multivalent-element-based oxybarometers to individual grains are (1) the ability to cover the entire oxygen fugacity $\left(f \mathrm{O}_{2}\right)$ range encountered in nature, and (2) the increased reliability from consistent results for semiindependent $f \mathrm{O}_{2}$ proxies. $f \mathrm{O}_{2}$ values were inferred from each mineral valence determination after correcting with available laboratory-experiment-derived, valence-specific partition coefficients to obtain melt valences and then calibrating with the $f \mathrm{O}_{2}$ values of the relevant equal species proportions points suggested for igneous (primarily basaltic) systems.

The resulting olivine and pyroxene valences are highly reduced and similar in the two meteorites with substantial fractions of $\mathrm{Cr}^{2+}, \mathrm{Ti}^{3+}$ and $\mathrm{V}^{2+}$. The exception is $\mathrm{Cr}$ in NWA 7325 pyroxene which is much more oxidized than the $\mathrm{Cr}$ in its olivine. Chromium and $\mathrm{Ti}$ in plagioclase in NWA 7325 is relatively oxidized (V valence not determined). The anomalously oxidized Cr in NWA 7325 pyroxene may be due to a secondary reheating event that oxidized $\mathrm{Cr}$ in the pyroxene without similarly oxidizing Ti and V. Such a separation of the redox couples may be an effect of re-equilibration kinetics, where the valence of $\mathrm{Cr}$ would be more rapidly modified. These valences yielded similar mean $f_{2} \mathrm{~S}$ for the two meteorites; IW-3.1 \pm 0.2 for NWA 7325 and IW-2.8 \pm 0.2 for Y-791538, consistent with an origin of NWA 7325 in either Mercury or an asteroid that experienced redox conditions similar to those on the ureilite parent body.
\end{abstract}




\section{INTRODUCTION}

Northwest Africa (NWA) 7325 is an ancient refractory achondrite suggested to be a possible Mercury sample based on bulk element ratios, very low Fe content and comparison with Messenger data (Weider et al., 2012, Irving et al., 2013). Subsequent studies suggested that an asteroidal origin was more likely (Goodrich et al., 2014a, Barrat et al., 2015, Weber et al., 2016). NWA 7325 consists of Mg-rich olivine (Fo 98) and diopside (Mg\# 98), Ca-rich plagioclase (An 90), and traces of Cr-rich sulfide and Fe,Ni metal (Irving et al., 2013, Goodrich et al., 2014a, Barrat et al., 2016, Weber et al., 2016). In terms of modal mineralogy and mineral compositions, it is unique compared with all known meteoritic materials other than a rare feldspathic lithology found as clasts in polymict ureilites. It has been interpreted to be a cumulate rock that crystallized from a refractory, incompatible element-depleted melt on a previously unsampled parent body (Goodrich et al., 2014a, Barrat et al., 2016, Weber et al., 2016). Goodrich and coworkers (2014a) suggested that this body might have had a differentiation history similar to that of the ureilite parent body.

Because of its apparent refractory nature, we have applied microscale X-ray Absorption Near Edge Structure (XANES) spectroscopy methods to determine valences of multivalent elements in the silicates (olivine, pyroxene and plagioclase) in an attempt to constrain the oxidation state of the crystallizing igneous system. Redox equilibria involving multivalent elements are useful for this purpose because they are sensitive to differing oxygen fugacity $\left(f \mathrm{O}_{2}\right)$ regimes and therefore provide a wide dynamic range in oxidation state conditions (e.g., Papike et al., 2005).

This work specifically focuses on valences of the first-row transition metals $\mathrm{Ti}, \mathrm{V}$ and $\mathrm{Cr}$, multivalent elements selected because they have redox couples that span the suspected range of $\mathrm{fO}_{2}$ experienced by these and other achondritic meteorites. The relevant redox couples are

$\mathrm{Ti}^{3+} \leftrightarrow \mathrm{Ti}^{4+}, \mathrm{V}^{2+} \leftrightarrow \mathrm{V}^{3+}$, and $\mathrm{Cr}^{2+} \leftrightarrow \mathrm{Cr}^{3+}$. The review by Papike and coworkers (2005) estimated that the $\mathrm{fO}_{2} \mathrm{~s}$ at which the coupled species are in equal proportions are at or below the ironwustite (IW) equilibrium: IW-7, IW-4 and IW, respectively. Since these are all single electron equilibria, the transitions from $10 \%$ to $90 \%$ of the reduced species occur over $7.6 \log$ units $( \pm \sim 4)$ 
in $f \mathrm{O}_{2}$ (Schreiber, 1986). Thus, the usable ranges for the three equilibria are approximately $\mathrm{Ti}=$ IW-11 to IW-3, V = IW-8 to IW, and Cr = IW-4 to IW+4, indicating that adjacent members of the three-element system have significant overlap and the entire three-element system has continuous coverage from $\sim$ IW- 11 to IW+4.

The valence dependences of K XANES ( $\mathrm{x}$-ray absorption spectra due to electronic transitions from the innermost $\mathrm{K}$ electron shell) for $\mathrm{Ti}, \mathrm{V}$ and $\mathrm{Cr}$ are well-studied and most valence determination methods use the energies and/or intensities of pre-edge peaks produced by bound-state electronic transitions. For Ti, Waychunas (1987) examined Ti XANES spectra for minerals and interpreted the effects of bond distance, valence and site geometry. Farges et al. (1997) documented the dependence of the energy and intensity of the pre-edge peak for $\mathrm{Ti}^{4+}$. Simon et al. (2008) expanded on this approach to include $\mathrm{Ti}^{3+}$ species in octahedral coordination allowing valence and coordination to be quantified in mafic silicates. Paque et al. (2013) applied the method to spinel in refractory meteoritic inclusions. Vanadium is a particularly significant element because of its many possible valence states $\left(\mathrm{V}^{2+}, \mathrm{V}^{3+}, \mathrm{V}^{4+}, \mathrm{V}^{5+}\right)$ translating into a wide dynamic $f \mathrm{O}_{2}$ range. The energy and intensity systematics of $\mathrm{V} K$ XANES spectra were documented by Wong et al. (1984). A quantitative approach for determining $\mathrm{V}$ valence based on pre-edge peak intensity was developed by Sutton et al. (2005) and applied to various earth and planetary materials (e.g., Karner et al., 2006, Karner et al., 2008, Righter et al., 2011, Papike et al., 2013). $\mathrm{Cr}^{2+} / \mathrm{Cr}^{3+}$ ratios based on K XANES have also been widely applied (e.g., Sutton et al., 1993, Berry et al., 2004, Berry et al., 2006, Karner et al., 2007a,b, Goodrich et al., 2013).

Few studies have applied multiple, XANES-based oxybarometers to individual mineral grains. Righter et al. (2011) applied Cr and V XANES to experimental garnet/melt pairs and found that $\mathrm{Cr}$ remains in $3+$ valence in garnet across a wide range of $f \mathrm{O}_{2} \mathrm{~s}(\mathrm{IW}-2$ to IW+9) whereas V exhibits variable average valence from 2.5 to 3.7. Karner et al. $(2007 \mathrm{a}, \mathrm{b})$ studied $\mathrm{Cr}$ and $\mathrm{V}$ valence partitioning in pyroxene crystallized from a martian composition melt. Trivalent $\mathrm{Cr}$ was found to be more compatible in the pyroxene structure than divalent $\mathrm{Cr}$, and thus an increasing partition coefficient $\mathrm{D}_{\mathrm{Cr}}$ for both augite/melt and pigeonite/melt with increasing $f \mathrm{O}_{2}$ is a function of the increased activity of $\mathrm{Cr}^{3+}$ in the crystallizing melt. The similar valence of $\mathrm{V}$ in glass and pyroxene at IW-1 suggested that $\mathrm{V}^{2+}$ and $\mathrm{V}^{3+}$ have similar compatibilities in pyroxene. 
In the present work, we studied NWA 7325 and a very reduced ureilite, Y-791538 (Goodrich et al., 2013), and report for the first time valence results for three multivalent elements in individual silicate grains. We also discuss the implications of the results for the origin of the NWA 7325 ungrouped achondrite.

\section{SAMPLES AND METHODS}

\subsection{Samples}

Two samples were analyzed in this work: ungrouped achondrite NWA 7325 and ureilite Y-791538. This particular ureilite was selected for comparison because its olivine is one of the most forsteritic (most reduced) and has been found to have very reduced $\mathrm{Cr}$ (Goodrich et al., 2013). Both samples were in the form of thin sections produced on pure silica slides and derived from small fragments of the meteorites. The Zeiss EVO 50 XVP scanning electron microscope at U. Mass. was used for initial characterization studies using secondary electron imaging (SEI), backscattered electron imaging (BEI) and energy dispersive spectrometry (EDS). Olivine (forsterite) and pyroxene (ortho- and clinopyroxene) for XANES analysis were identified primarily using BEI. We also analyzed plagioclase grains in NWA 7325. Within each selected grain, SEI and BEI were used to locate core areas unaffected by in situ alteration for XANES analysis. Cr XANES spectra were also collected for various Cr-rich inclusions in NWA 7325 pyroxene; these were targeted using $\mathrm{Cr} \mathrm{K} \alpha$ maps and selecting locations of maximum $\mathrm{Cr} \mathrm{K} \alpha$ fluorescence intensity, typically a factor of three greater than that from the host pyroxene. Olivine and pyroxene are homogeneous in both samples. NWA 7325 has olivine Fo $97.5 \pm 0.1$ and diopside (clinopyroxene) Wo $45.3 \pm 0.2, \mathrm{mg} \#$ 98.2 \pm 0.2 . Y-791538 has olivine Fo 91.3 \pm 0.1 and two pyroxenes, pigeonite Wo 9.4 $\pm 0.6, \mathrm{mg} \#$ 91.2 \pm 0.4 (Tribaudino, 2006) and orthopyroxene (opx) Wo $4.9 \mathrm{mg \#} \mathrm{92.5.} \mathrm{In} \mathrm{this} \mathrm{paper,} \mathrm{"cpx"} \mathrm{is} \mathrm{used} \mathrm{to} \mathrm{refer} \mathrm{to} \mathrm{diopside} \mathrm{in} \mathrm{NWA} 7325$ and pigeonite in Y-791538. Figures 1 and 2 show whole section backscattered electron image (BEI) collages for NWA 7325 and Y-791538, respectively, with the grains analyzed by XANES

indicated. Further details of texture and mineral compositions for NWA 7325 are given in Goodrich et al. (2014a), Barrat et al. (2015) and Weber et al. (2016). Y-791538 is described in Goodrich et al. (2013). 


\subsection{XANES Instrumentation}

Chromium XANES spectra were collected using the x-ray microprobes at Beamline X26A at the National Synchrotron Light Source (NSLS), Upton, NY, and Beamline 13-ID-E (GSECARS) at the Advanced Photon Source (APS), Argonne, IL. Titanium and V XANES spectra were collected using the APS x-ray microprobe.

At NSLS, a channel-cut $\mathrm{Si}(111)$ monochromator was used to feed monochromatic, bending magnet x-rays to a dual Kirkpatrick-Baez (KB) mirror system which focused the beam to $\sim 7 \mu \mathrm{m}$ (Sutton et al., 2002). At APS, a cryogenic, dual-crystal, Si(111) monochromator was used to feed monochromatic, undulator x-rays to a dual KB mirror system which focused the beam to $\sim 1 \mu \mathrm{m}$ (Sutton et al., 2002). In both systems, relative to the incident $\mathrm{x}$-ray beam, the thin section surface was oriented at $45^{\circ}$ and the fluorescence detector was at $90^{\circ}$ within the plane of the synchrotron (the position of minimum scattered x-ray intensity from the linearly-polarized source).

XANES spectra were recorded in fluorescence mode using quad Vortex Silicon Drift Detectors (SDD) to collect $\mathrm{K} \alpha$ intensities as the incident energy was scanned through the appropriate absorption edges. Energy calibration was based on first derivative peak energies in metal foil spectra collected in transmission with ion chambers $(\mathrm{Ti} \equiv 4966 \mathrm{eV} ; \mathrm{V} \equiv 5465 \mathrm{eV} ; \mathrm{Cr} \equiv$ $5989 \mathrm{eV}$ ). Titanium K XANES spectra were collected in $5 \mathrm{eV}$ steps from 4920 to $4960 \mathrm{eV}, 0.1$ eV steps from 4960 to $4990 \mathrm{eV}$, and $2.0 \mathrm{eV}$ steps from 4990 to $5200 \mathrm{eV}$. Vanadium K XANES spectra were collected in $2.5 \mathrm{eV}$ steps from 5365 to $5455 \mathrm{eV}, 0.2 \mathrm{eV}$ steps from 5455 to 5490 $\mathrm{eV}$, and $2.0 \mathrm{eV}$ steps from 5490 to $5700 \mathrm{eV}$. Chromium K XANES spectra were collected in 5 $\mathrm{eV}$ steps from 5960 to $5980 \mathrm{eV}, 0.2 \mathrm{eV}$ steps from 5980 to $6015 \mathrm{eV}$, and $2.5 \mathrm{eV}$ steps from 6015 to $6100 \mathrm{eV}$. Dwell times were between 1 and 10 seconds.

\subsection{Valence Determination from XANES}

\subsubsection{Titanium}

Titanium valences were obtained using the energy and intensity of the $1 \mathrm{~s} \rightarrow 3 \mathrm{~d}$ pre-edge peak (Simon et al., 2008, 2016). The approach is based on the expectation that $\mathrm{Ti}\left(\mathrm{Ti}^{3+}, \mathrm{Ti}^{4+}\right.$ ) will occur either in octahedral or tetrahedral coordination in the silicates of interest. Farges et al. (1997) showed that tetrahedral $\mathrm{Ti}^{4+}$ XANES spectra have a very intense pre-edge peak and that the peak for octahedral $\mathrm{Ti}^{4+}$ has much lower intensity and lies at higher centroid energy. $\mathrm{Ti}^{3+}$ is 
expected to be predominantly in octahedral coordination (e.g., Dowty and Clark, 1973, Lombard et al., 2009) and its pre-edge peak will therefore also be of low intensity and at lower centroid energy than octahedral $\mathrm{Ti}^{4+}$ (Figure $3 \mathrm{a}$ ). Thus, these three endmembers lie at distinct positions on an intensity-energy plot (Figure 3b). We used the following standards (single crystals except the $\mathrm{Ti}^{3+}$ standard) to define the apices of this valence-coordination field: synthetic forsterite containing $1 \mathrm{wt} \% \mathrm{Ti}\left(\mathrm{Ti}^{4+}{ }_{\text {tet }}\right.$; synthesized by Jun Ito at the University of Chicago; produced in air), natural acmite $\left(\mathrm{Ti}^{4+}{ }_{\text {oct }}\right.$; Norway), and a synthetic acmite-structured $\mathrm{NaTi}^{3+} \mathrm{Si}_{2} \mathrm{O}_{6}\left(\mathrm{Ti}^{3+}{ }_{\text {oct}}\right.$; Prewitt et al., 1972). The centroid energy (4966-4972 eV after background subtraction; $\mathrm{E}$ in $\mathrm{eV}$ ) and normalized maximum intensities (\%oI) were determined for each of these phases, leading to $\left(\mathrm{Ti}^{4+}{ }_{\text {tet }}, 4969.50,930\right),\left(\mathrm{Ti}^{4+}{ }_{\text {oct }}, 4970.40,100\right)$ and $\left(\mathrm{Ti}^{3+}{ }_{\text {oct }}, 4969.50,76\right)$. Values for the single crystals were for merges of spectra collected at differernt orientations.

Mixing curves were determined between pairs of the three end-member components by producing and fitting synthetic spectra of known proportions of the $\mathrm{Ti}$ species, the $\mathrm{Ti}^{4+}{ }_{\text {tet }}-\mathrm{Ti}^{4+}{ }_{\text {oct }}$ mixing line being slightly non-linear (Figure 3b). The relative amounts of $\mathrm{Ti}$ in the different valence states and coordination geometries were obtained by applying the lever rule to the “ $\mathrm{Ti}^{4+}{ }_{\text {tet }}-\mathrm{Ti}^{4+}{ }_{\text {oct }}-\mathrm{Ti}^{4+}{ }_{\text {oct }}$ " mixing field. Resulting $\mathrm{Ti}$ valences are reported as values between 3 and 4. To minimize orientation effects (see below), valences are also reported for mean values of each mineral type. Intensity and centroid precision were determined to be $5 \%$ and $0.05 \mathrm{eV}(1 \sigma)$, respectively, based on repeats of spectral processing (normalization and background subtraction). Valence precision was defined by the values obtained by plugging these ranges into the calibration algorithm. Uncertainties in calibration values were negligible compared to these precision ranges.

Two pieces of evidence document the validity of this approach. Titanium valence was previously determined (Simon et al, 2007) using an electron probe microanalyzer for Allende (carbonaceous chondrite) fassaite, a Ti-, Al-rich clinopyroxene in which Ti concentrations were sufficiently high $\left(>4 \% \mathrm{TiO}_{2}\right)$ that $\mathrm{Ti}^{3+}$ contents could be reliably determined by stoichiometric methods. The overall agreement was generally good with the XANES valences systematically higher than the electron probe result by about 0.1 , a value whose magnitude is comparable to the $2 \sigma$ uncertainty. In a Murchison (carbonaceous chondrite) hibonite grain analyzed by Beckett et al. (1986), ESR data indicated $15-28 \%$ of the Ti was trivalent corresponding to an average $\mathrm{Ti}$ 
valence of 3.72-3.85, indistinguishable from our XANES results for hibonite-bearing inclusions of 3.73 and 3.82 (Simon et al., 2009). These comparisons suggest the accuracy is comparable to the precision in our measurements (between 0.05 and $0.13,1 \sigma$ ).

XANES spectra for anisotropic crystals can have an orientation effect because the exciting synchrotron radiation is linearly-polarized. No attempt was made in the present work to correct for orientation effects or to include potential errors in the error analysis. Consequently, any such effects that are significant will increase the dispersion of a given grain population (e.g., Cr valence in olivine from NWA 7325). The fact that the standard error of the mean valences in these datasets is small (typically $<0.05$ ) indicates that such orientation effects are minor.

\subsubsection{Vanadium}

The $\mathrm{V}$ valence method (producing determinations for $\mathrm{V}^{2+}, \mathrm{V}^{3+}, \mathrm{V}^{4+}$ and $\mathrm{V}^{5+}$ ) followed that of Sutton et al. (2005) using the edge-step-normalized intensity of the $1 \mathrm{~s} \rightarrow 3 \mathrm{~d}$ pre-edge peak $(\sim 5470 \mathrm{eV})$. Pre-edge peak intensity increases systematically as valence becomes more oxidized (Figure 4a). Valence calibration (pre-edge peak intensity versus valence; Figure 4b) was based on XANES spectra of Fe-, alkali-free haplobasaltic glass standards (polished thick disks) of Schreiber and Balazs (1982) with the assumption that $\mathrm{V}^{2+}$ yields no pre-edge peak intensity (Wong et al., 1984). Divalent and trivalent V, the most relevant species for the samples studied here, have relatively weak pre-edge peak intensities of 0 and 115 , respectively, expressed in permil (Sutton et al., 2005). To minimize orientation effects, mean valences are reported for each mineral type. Intensity precision was determined to be $5 \%(1 \sigma)$ based on repeats of spectral processing (normalization and background subtraction) and valence precision was therefore 0.05 $(1 \sigma)$.

This calibration (Figure 4b) has yielded good agreement with known V valences ranging from 3 to 5 in natural and synthetic crystals where the valences are known from stoichiometry (Righter et al., 2006, 2011). Intensity results for $\mathrm{V}$-bearing spinel $\left(\mathrm{Mg}_{3} \mathrm{~V}^{5+}{ }_{2} \mathrm{O}_{8}\right.$ and $\left.\mathrm{MgV}^{3+}{ }_{2} \mathrm{O}_{4}\right)$ and cavansite $\left(\mathrm{V}^{4+}\right)$ (from Righter et al. 2006), and the synthetic goldmanite $\mathrm{Ca}_{3} \mathrm{~V}^{3+}{ }_{2} \mathrm{Si}_{3} \mathrm{O}_{12}$ (Righter et al., 2011) agree with this calibration within precision. This agreement suggests that valence accuracy is comparable to precision in our measurements of $0.05(1 \sigma)$. As described for $\mathrm{Ti}$, no attempt was made in the present work to correct for orientation effects or to include 
potential errors in the error analysis and small standard error of the mean valences (typically < 0.05) indicates that such orientation effects are minor.

\subsubsection{Chromium}

The $\mathrm{Cr}$ valence method used the normalized intensity of the derivative spectrum peak (Figure 5) produced by a $1 \mathrm{~s} \rightarrow 4 \mathrm{~s}$ electronic transition (Berry et al., 2004). This transition is dipole forbidden but its probability is increased through molecular orbital mixing. Each XANES spectrum was first smoothed with a 3-point algorithm for five iterations, then pre-edge and postedge normalized to produce normalized spectra with values of zero at low energy and unity at high energy. The intensity of the $\mathrm{Cr}^{2+}$-sensitive peak was then determined to be the value at the apex in the derivative of each spectrum. Intensity precision were determined to be $5 \%(1 \sigma)$ based on repeats of spectral processing (normalization and background subtraction) and valence precision was therefore $0.05(1 \sigma)$.

Two glass standards (CMAS doped with Cr; polished thick disks) were used (Hanson and Jones, 1998); a $\mathrm{Cr}^{2+}$ standard produced under highly-reducing conditions (sealed with graphite; $\mathrm{Cr}$ valence $\equiv 2.00)$ and a $\mathrm{Cr}^{3+}$ standard produced under highly-oxidizing conditions $\left(\mathrm{CO}_{2} ; \mathrm{Cr}\right.$ valence $\equiv 3.00$ ). The derivative peak intensities for the standards were 0.21 and 0.01 , respectively (Figure 5). Intermediate valences were quantified by linear interpolation of these endmember peak intensities; linear interpolation is appropriate since the intensity used is due to a single transition and is proportional to the fraction of $\mathrm{Cr}$ in the $\mathrm{Cr}^{2+}$ state. To minimize orientation effects, known to be significant for Cr XANES in these minerals (e.g., Goodrich et al., 2013), Cr K XANES spectra for each grain were collected at four orthogonal orientations (obtained by rotating the thin section in 90 degree increments). The valence for each grain is reported as that obtained for a synthetic spectrum produced by merging the spectra for the four orientations. In addition, mean valences are reported for each mineral type. This approach was demonstrated to be valuable in a recent Cr XANES study of ureilites (Goodrich et al., 2013).

The $\mathrm{Cr}^{2+}$-sensitive derivative peak occurs at slightly difference energies in olivine, pyroxene and glass. Although these precise peak energies are not used in the valence determination, it is important to understand these systematics in order to select appropriate energies at which to extract intensities. These systematic differences were documented with XANES spectra for the following endmember samples: $\mathrm{Cr}^{2+}$ and $\mathrm{Cr}^{3+}$ glass standards described 
above; $\mathrm{Cr}^{3+}$ dominated olivine (Ito; crystallized in air); $\mathrm{Cr}^{2+}$ dominated olivine (average high-Fo ureilite); $\mathrm{Cr}^{3+}$ dominated pyroxene (San Carlos opx and cpx); $\mathrm{Cr}^{2+}$ dominated pyroxene (high-Fo ureilite, PCA82506). These data (Figure 6) show that, relative to the glass spectral peak, the $\mathrm{Cr}^{2+}$ peaks for olivine and pyroxene are at +0.7 and $+1.8 \mathrm{eV}$, respectively.

We expect the intensities of the standards to be appropriate for both olivine and pyroxene based on the expectation that $\mathrm{Cr}$ will occur predominately in octahedral coordination in both (Hanson and Jones, 1998). To test this suitability, we analyzed a $\mathrm{Cr}^{2+}$-dominated forsterite as an unknown. This synthetic, powder specimen (GRR-1690; G. Rossman, Caltech) had a nominal stoichiometric composition of $\mathrm{Mg}_{1.9} \mathrm{Cr}^{2+}{ }_{0.1} \mathrm{SiO}_{4}$ and derived from the study of Scheetz and White (1972; most likely run 20) in which forsterite was crystallized in a highly-reducing, argon-filled, arc furnace using a graphite crucible. Reflectance spectra (Scheetz and White, 1972) showed the presence of minor $\mathrm{MgCr}^{3+}{ }_{2} \mathrm{O}_{4}$ in addition to the forsterite. Thus, our valence result of $2.12 \pm 0.05$ (Goodrich et al., 2013) for this powder validates the forsterite valence determination approach used here. The San Carlos opx and cpx yielded similar valences $(3.00 \pm 0.05$ and $2.99 \pm 0.05$, respectively) and comparable to $\mathrm{Cr}^{3+}$-dominated olivine $(2.90 \pm 0.05)$. The valence for pyroxene in the reduced ureilite PCA82506 was $2.15 \pm 0.05$ comparable to that of its olivine $(2.20 \pm 0.05)$ providing additional evidence that the glass calibration is appropriate for both olivine and pyroxene and that accuracy is comparable to precision of our measurements $(0.05$ $1 \sigma)$. As described for $\mathrm{Ti}$, no attempt was made in the present work to correct for orientation effects or to include potential errors in the error analysis and small standard error of the mean valences (typically $<0.05$ ) indicates that such orientation effects are minor.

\section{$2.4 \mathrm{fO}_{2}$ Interpretation}

The valences determined using the methodology described above can, in principle, be used as proxies for inferring the $f_{2}$ of the melt from which the minerals crystallized. Ideally, such inferences could be obtained from the valence proxies in silicates using the results of crystallization experiments conducted under controlled (and varied) $\mathrm{fO}_{2}$ thus providing "mineral valence - $f \mathrm{O}_{2}$ " calibration curves. However, such complete data sets are extremely rare. 
Instead, we have used the following two-step approach. First, the crystal valence, expressed as the ratio of the reduced species to the oxidized species, $F_{\text {crystal }}$, is divided by the ratio of the valence-specific partition coefficients, $R_{D}$, to obtain the species ratio in the melt, $F_{\text {melt }}$ :

$$
F_{\text {melt }}=F_{\text {crystal }} / R_{D}
$$

where

$$
R_{D}=D_{\text {crystalmelt }}(\text { reduced species }) / D_{\text {crystalmelt }}(\text { oxidized species })
$$

Values for $R_{D}$ were obtained from literature results of crystallization experiments (see Results section). Second, $F_{\text {melt }}$ is compared to the $f \mathrm{O}_{2}$ of the relevant redox equilibria to calculate $f \mathrm{O}_{2}$ of the melt. We used the single electron redox formalism of Schreiber (1986):

$$
-\log \left(f \mathrm{O}_{2}\right)=4 * \log \left(F_{\text {melt }}\right)+\mathrm{B}
$$

where B "incorporates all quantities that are functions of temperature and/or base composition." For any arbitrary $F_{\text {melt }}$, the $f \mathrm{O}_{2}, \delta$, relative to that of the redox equal proportions state, $\beta$, (expressed in log units relative to the IW buffer) is therefore given by

$$
\delta=-4 * \log \left(F_{\text {melt }}\right)
$$

The $f \mathrm{O}_{2}(\Delta \mathrm{IW})$ corresponding to $F_{\text {melt }}$ is then $\beta+\delta$.

Thus, the main challenge in these calculations is obtaining appropriate values for $R_{D}$ (the valence-specific partitioning coefficient ratios) and $\beta$ (redox equal proportion $f \mathrm{O}_{2}$ ). In the case of $\mathrm{Cr}$ in olivine, Hanson and Jones (1998) have provided an appropriate equation for converting $\mathrm{Cr}$ valence in basaltic melt directly to $\mathrm{fO}_{2}$ (relative to IW). The uncertainties in the $\mathrm{fO}_{2}$ determinations are primarily the uncertainties in $\mathrm{R}_{\mathrm{D}}$ which we liberally estimate to be about $\pm 50 \%$ for $\mathrm{Ti}$ and $\mathrm{V}$. The errors are smaller for $\mathrm{Cr} ; \sim \pm 10 \%$ for olivine and $\pm 30 \%$ for pyroxene. These uncertainties lead to $f \mathrm{O}_{2}$ uncertainties from 0.6 to $0.9 \log$ units for individual minerals.

The calculated equilibration temperature for NWA 7325 is $\geq 1180{ }^{\circ} \mathrm{C}$ (Goodrich et al., 2014a), based on the distribution of Ca between olivine and augite (Köhler and Brey, 1990). This is similar to Ca distribution temperatures for ureilites and a few brachinites. Other common mineral thermometers, such as the two-pyroxene thermometer or the olivine-spinel thermometer, cannot be used for NWA 7325 due to the lack of appropriate mineral assemblages. Y-791538 has an estimated equilibration temperature of $1240{ }^{\circ} \mathrm{C}$ based on the two-pyroxene thermometer 
(Takeda, 1989). The equilibration temperatures near $1200{ }^{\circ} \mathrm{C}$ suggest that the "Cr valence- $f \mathrm{O}_{2}$ " relationships determined experimentally by Hanson and Jones (1998) for olivine is applicable to olivine in NWA 7325 and Y-791538.

\section{RESULTS}

\subsection{Valences in Crystals}

The valence results for $\mathrm{Cr}, \mathrm{Ti}$ and $\mathrm{V}$ in olivine, pyroxene and plagioclase are given in Tables 1 and 2 for NWA 7325 and Y-791538, respectively. Representative XANES spectra are shown in Figure 7. All results are for individual grains denoted in Figures 1 and 2. Cr valence results from NSLS analyses are reported for orientation-merged spectra (see section 3.1.1). In this way, a single valence result was obtained for each element in each grain. Weighted mean valences (using the inverse of the square of the $1 \sigma$ uncertainties as weights) were calculated for the valence data for a given element in a given mineral. The uncertainty in the mean valence values was taken as the standard error of the mean, $\sqrt{ }\left(1 / \sum \sigma_{i}^{-2}\right)$. These results are summarized in Figure 8 .

\subsubsection{Chromium}

Twenty-four (24) analyses were obtained on 15 olivine grains (OL1-15) in NWA 7325 using both APS and NSLS. The NSLS olivine analyses each consists of a merged spectrum combining spectra at different crystal orientations (see Goodrich et al., 2013). For cpx, 15 analyses were obtained on 14 grains (PX1-14). Four plagioclase analyses were collected (PLAG1-4). The mean valences for the three minerals were olivine $=2.08 \pm 0.01, \mathrm{cpx}=2.69 \pm$ 0.01 , and plagioclase $=2.83 \pm 0.03$. Thus, $\mathrm{Cr}$ in the olivine is close to pure $\mathrm{Cr}^{2+}$ whereas the cpx and plagioclase are $\mathrm{Cr}^{3+}$ dominated. This situation can also be seen in the XANES spectra (Figure 7) where the cpx and plagioclase absorption edge energies are similar and the olivine edge is at lower energy (more reduced). Cr XANES spectra collected for various inclusions in cpx showed that the majority were dominated by $\mathrm{Cr}^{2+}$.

In Y-791538, seven (7) analyses were obtained on 7 olivine grains (OL1-7) where each consists of a merged spectrum combining spectra at different crystal orientations. Five analyses were obtained on five cpx grains (PIG1-5) and seven analyses on 7 opx grains (OPX1-7). The mean valences for the three minerals were olivine $=2.10 \pm 0.02, \mathrm{cpx}=2.06 \pm 0.02$, and opx $=$ 
$2.08 \pm 0.02$. Thus, $\mathrm{Cr}$ in all three minerals is close to pure $\mathrm{Cr}^{2+}$. The absorption edge energies of all three spectra are also similar (Figure 7).

\subsubsection{Titanium}

Titanium K XANES spectra for NWA 7325 were obtained at the APS on seven olivine grains (OL5, 6, 7, 8, 9, 11, 13), eleven pyroxene (cpx) grains (PX1a,5,6,7,8,9,10,11,12,13,14), and one plagioclase grain (PLAG1). The mean valences for the three minerals were olivine $=$ $3.47 \pm 0.02, \operatorname{cpx}=3.64 \pm 0.02$, and plagioclase $=3.74 \pm 0.09$. The reduced level of the olivine indicated a significant content of $\mathrm{Ti}^{3+}$; such high levels of $\mathrm{Ti}^{3+}$ are seen typically only in CAI fassaite (Simon et al., 2007). Cpx and plagioclase have comparable and more oxidized, $\mathrm{Ti}^{4+}$ dominated, valences but the presence of minor $\mathrm{Ti}^{3+}$ is still apparent in both. Tetrahedral coordination is low in all three minerals, being lowest in olivine $(11 \%)$ and higher in pyroxene and plagioclase (26 and 35\%, respectively).

For Y-791538, spectra were collected for five olivine grains (OL1-5), five clinopyroxene grains (PIG 1-5) and five orthopyroxene grains (OPX 1, 2, 5, 6, 7). The mean valences for the three minerals were olivine $=3.36 \pm 0.03, \mathrm{cpx}=3.64 \pm 0.05$, and opx $=3.68 \pm 0.05$. As in NWA 7325 , olivine has reduced $\mathrm{Ti}$ with significant content of $\mathrm{Ti}^{3+}$. Cpx and opx have comparable and more oxidized, $\mathrm{Ti}^{4+}$-dominated, valences. Tetrahedral coordination contents are comparable to those in NWA 7325, with lower values in olivine (11\%) and higher in pyroxene (42\%).

\subsubsection{Vanadium}

Vanadium K XANES spectra for NWA 7325 were obtained (Figure 1) for five olivine grains (OL6,7,8,11,13), seven pyroxene grains (PX1a,5,6,8-11) and six plagioclase grains (PLAG2-4,6-8). The similarity of the spectra suggested orientation effects are minor. The olivine spectra were dominated by $\mathrm{V}^{2+}$ and the pyroxene spectra by $\mathrm{V}^{3+}$. The valence results for olivine, pyroxene, and plagioclase were $2.42 \pm 0.02,2.66 \pm 0.02$ and $3.35 \pm 0.02$, respectively.

For Y-791538, spectra were collected (Figure 2) for five olivine grains (OL1-5), five clinopyroxene grains (PIG1-5) and five orthopyroxene grains (OPX1,2,5,6,7). The resulting mean valences of olivine $=2.48 \pm 0.02$, pigeonite $=2.66 \pm 0.02$, and orthopyroxene $=2.65 \pm$ 0.02. The $\mathrm{V}$ valences for olivine and cpx are comparable to those obtained for those phases in NWA 7325 (Figure 8). 


\section{2 $f^{\mathrm{O}_{2}}$ of Melts}

As mentioned above, these calculations require (1) the $f \mathrm{O}_{2}$ of the relevant redox equilibria, and (2) ratios of valence-specific partitioning coefficients.

\subsubsection{Redox equilibria}

The most appropriate determination of the $f \mathrm{O}_{2}$ at which $\mathrm{Cr}^{2+} \mathrm{Cr}^{3+}$ exist in equal proportions in silicate melt is provided by the mid-ocean ridge basalt (MORB) experiments of Hanson and Jones (1998). That work investigated three slightly different MORB starting compositions (MORB1, MORB2, MORB3) each doped with $\mathrm{Cr}$ and $\mathrm{V}$ at a fraction of a percent level and run at 1250,1200 and $1200{ }^{\circ} \mathrm{C}$, respectively. These temperatures are close to the $\sim 1200$ ${ }^{\circ} \mathrm{C}$ equilibration temperature estimated for NWA 7325. The three valence equal proportions values calculated from these equations were $\mathrm{IW}+1.3, \mathrm{IW}+1.3$ and $\mathrm{IW}+1.7$, respectively (using the equations in their Table 5). Also quoted in that paper is an unpublished "basalt" equation $\left(1260{ }^{\circ} \mathrm{C}\right.$ ) from J. Delano (SUNY-Albany) which yields an equal proportions point of IW+1.8. Since the difference between these values is small compared to other sources of uncertainty in this work, we have used the average of these values, i.e., IW +1.5 . This value is about an order of magnitude more oxidized than that indicated in Papike et al. (2016; IW+0.5; their Figure 1).

The most appropriate determinations of the $f \mathrm{O}_{2}$ at which $\mathrm{Ti}^{3+}$ and $\mathrm{Ti}^{4+}$ exist in equal proportions are provided by studies of refractory $\mathrm{Ca}-\mathrm{Al}$ inclusions (CAI) in carbonaceous chondrites (Beckett 1986; Simon et al., 2007). For Ti, crystallization experiments suggest that fassaite crystallized near the redox conditions of the solar nebula gas (i.e., IW-7; Beckett, 1986). However, estimating the $f \mathrm{O}_{2}$ condition where $\mathrm{Ti}^{3+}=\mathrm{Ti}^{4+}$ is complicated by the zonation in the synthetic and natural fassaites and the apparent crystallographic preference of clinopyroxene for $\mathrm{Ti}^{3+}$ (see below). The most reduced measured valences in the natural fassaites $(\sim 3.2$; Simon et al., 2007) are likely associated with solar conditions suggesting that the equal proportions point lies close to IW-7. This $f \mathrm{O}_{2}$ value is the same as that reported by Papike et al. (2016).

For $\mathrm{V}^{2+}-\mathrm{V}^{3+}$, the most appropriate determination of the equal proportions $f \mathrm{O}_{2}$ is provided by the valence results of experiments by Karner et al. (2007a) for synthetic martian basaltic melt. Their most reduced experiment, IW-1, yielded a $\mathrm{V}$ valence of 2.7 for the glass. Using equation (3), this suggests the equal valence point is $\sim 2 \log$ units more reduced than IW-1, i.e., $\sim$ IW-3. More reduced values (IW-4 and IW-6) have been suggested by Papike et al. (2005 and 2016, 
respectively) based on valences measured in CAI pyroxenes. For the present work, we use the IW-3 value suggested by the Karner et al. (2007a) experiments because it is based on measurements on experimental glass rather than crystals, and therefore circumvents the need for valence-specific partitioning considerations.

Based on the above discussion, we estimate the uncertainty in the $\mathrm{Ti}, \mathrm{Cr}$, and $\mathrm{V}$ equal proportions points to be $\pm 0.5 \log$ units in $f \mathrm{O}_{2 .}$.

\subsubsection{Valence-specific partitioning coefficients}

Valence-specific partitioning coefficient ratios were obtained or inferred from various literature sources. These determinations are discussed for each element and the results are given in Table 3.

Chromium: For olivine, Hanson and Jones (1998) indicate that $\mathrm{D}\left(\mathrm{Cr}^{2+}\right)$ is temperature dependent and has a value of 1.0 for $1200{ }^{\circ} \mathrm{C}$ (their Figure 14a). $\mathrm{D}\left(\mathrm{Cr}^{3+}\right)$ has mainly a dependence on the parameter NBO/T (non-bridging oxygens per tetrahedrally-coordinated cation) and has a value of 1.0 for their MORB1 composition (NBO/T=0.8, their Figure 13c). Thus, the $R_{D}$ ratio is 1.0 , meaning that olivine has no preference for either divalent or trivalent Cr. Since the equilibration temperature of the ureilites is estimated to be $1200-1300{ }^{\circ} \mathrm{C}$ (Goodrich et al., 2013), we use a $R_{D}$ value of 0.9 for $\mathrm{Y}-791538$, appropriate for $1250{ }^{\circ} \mathrm{C}$ (Hanson and Jones, 1998, Figure 14a).

For pyroxene, we mainly have the augite and pigeonite crystallization experiments of Karner et al. (2007b) using a martian basalt composition at IW-1 to IW+1. XANES indicated the crystalline products were dominated by $\mathrm{Cr}^{3+}$. These data produce a linear (3-point) trend in $\mathrm{D}(\mathrm{Cr}$,augite $)$ vs $\mathrm{fO}_{2}$, a trend that is responsive mainly to the changing activity of $\mathrm{Cr}^{3+}$ since XANES showed $\mathrm{Cr}^{3+}$ dominating in the augite. Thus, the $R_{D}$ ratio must be $<1$. We have extrapolated this trend to more reducing conditions to infer $\mathrm{D}\left(\mathrm{Cr}^{2+}\right)$ and to more oxidizing conditions to infer $\mathrm{D}\left(\mathrm{Cr}^{3+}\right)$. At four orders of magnitude lower $f \mathrm{O}_{2}$ than the condition where $\mathrm{Cr}^{2+}$ $=\mathrm{Cr}^{3+}$ (i.e., IW-2.3), the melt will be $90 \% \mathrm{Cr}^{2+}$ (Schreiber, 1986) and the extrapolated $\mathrm{D}(\mathrm{Cr})$ is 5. At 4 orders of magnitude higher $\mathrm{fO}_{2}$ than the equal proportions point (i.e., IW-5.7), the melt will be $90 \% \mathrm{Cr}^{3+}$ and the extrapolated $\mathrm{D}(\mathrm{Cr})$ is 16 . This leads to a $R_{D}$ ratio of 0.3 , the appropriate value for the NWA 7325 diopside. For pigeonite, as in Y-791538, Karner et al. (2007b) found 
$\mathrm{D}(\mathrm{Cr})$ to be a factor of two lower than augite crystallized from the same melt. But this difference was considered by Karner et al. (2007b) to be a charge balance effect and not a difference in $\mathrm{Cr}^{2+} / \mathrm{Cr}^{3+}$ in the pyroxene. Consequently, the work of Karner et al. (2007b) suggests similar valence state partitioning for pigeonite and augite. In addition, ionic radii considerations suggest $\mathrm{Cr}^{2+}$ will substitute into the M2 site (Angel et al., 1988) and $\mathrm{Cr}^{3+}$ into $\mathrm{M} 1$ in all pyroxenes (Papike et al., 2005). Consequently, we use a $R_{D}$ ratio of 0.3 for $\mathrm{Cr}$ in all pyroxenes.

Vanadium: $\mathrm{V}^{2+}$ is expected to be more compatible than $\mathrm{V}^{3+}$ in olivine because its ionic size is well-suited to the M1 and M2 sites and charge balance is achieved (Papike et al., 2005) but the crystallization experiments that have been done under reducing conditions (e.g., Karner et al., 2008) yielded no olivine. We adopt an $R_{D}$ ratio of 2 here to reflect an expected slight preference for $\mathrm{V}^{2+}$ based on charge-balance considerations. Pyroxene might be expected to also have this charge-balance-based preference for $\mathrm{V}^{2+}$, however, the pyroxene that was produced in the Karner et al. (2008) experiments (augite and pigeonite) showed little valence-specific preference so we use a $R_{D}$ ratio of 1 for $\mathrm{V}$ in pyroxene.

Titanium: Titanium is the most difficult of the three elements for which to obtain partitioning information because $\mathrm{Ti}^{3+}$ is stable only under very reducing conditions where experiments are difficult to conduct. The fact that substantial $\mathrm{Ti}^{3+}$ is present in the mafic silicates from both NWA 7325 and Y-791538 strongly suggests that the partitioning ratio must be $>1$, i.e., strong preference for the reduced species. Few quantitative data exist. In a study of $\mathrm{Ti}^{3+}$ zoning in fassaite (Ti-rich pyroxene) grains in the Allende carbonaceous chondrite, Simon et al. (1991) noted that a factor of three preference for $\mathrm{Ti}^{3+}$ would explain the observed zonation. This value is supported by a recent crystallization experiment of an L6 chondrite composition melt at IW-3.7 which showed a $R_{D}$ ratio of 3.2 (Simon et al., 2014). We adopt a value of 3 for all pyroxene. In the C3 experiment described by Simon et al. (2014) (held at IW-2.5 then cooled at IW-0.5), the olivine was more reduced than the pyroxene by a factor of 1.6 leading to an $R_{D}$ ratio of 5 .

\subsection{3 $\mathrm{fO}_{2}$ results}

Calibration plots for "valence vs. $f \mathrm{O}_{2}$ " for olivine and pyroxene, based on equation 2 and applying valence-specific partition coefficient ratios, are shown in Figure 9. The $f \mathrm{O}_{2}$ results for NWA 7325 and Y-791538 are summarized in Table 3 expressed in log units relative to IW and 
plotted in Figure 10. We focus here on the early phases olivine and pyroxene because there is evidence that plagioclase has been remelted in both samples in secondary events (see Discussion). Origins in highly reducing environments are indicated for both meteorites. We describe the results below organized by element.

Chromium: We previously reported a Cr-valence in olivine based $f \mathrm{O}_{2}$ for non-chromite bearing ureilites of IW-1.9 to IW-2.8 (Goodrich et al., 2013) and the Cr result here for olivine in Y-791538 of IW-2.4 \pm 0.6 is in good agreement with the previous results. NWA $7325 \mathrm{Cr}$ in olivine yielded a slightly more reduced, though similar, value of IW-2.7 \pm 0.6 . For $\mathrm{Cr}$ in pyroxene, Y-791538 was IW-5 for both cpx and opx, while NWA 7325 was much more oxidized at IW+1. The extreme difference between the pyroxene results may reflect the effects of secondary reheating (more on this in the Discussion section).

Vanadium: For both rocks, $f \mathrm{O}_{2}$ estimates based on vanadium valences were slightly more oxidized but generally consistent with those based on $\mathrm{Cr}$ in olivine. Values for olivine and pyroxene ranged from IW-2.4 to IW-1.8 with uncertainties of \pm 0.9 .

Titanium: $\mathrm{fO}_{2}$ results based on Ti valence are more reduced than those based on $\mathrm{V}$ and $\mathrm{Cr}$ in olivine. Values were IW-4.1 \pm 0.7 (pyroxene) to IW-4.4 \pm 0.9 (olivine) for NWA 7325 and IW-3.8 \pm 0.8 to IW-5.2 \pm 0.9 for Y-791538. The mean values for the two rocks are similar at IW-4.3 \pm 0.5 , about 1-2 $\log$ units more reduced than the inferences from $\mathrm{V}$ and $\mathrm{Cr}$ in olivine.

Figure 10 also shows an overall weighted mean value for each meteorite. These were calculated as weighted means using the inverse of the $1 \sigma$ uncertainties in $\Delta \mathrm{IW}$ as the weights. The results for $\mathrm{Cr}$ in pyroxene were excluded in these calculations because of possible perturbation by secondary events (see Discussion section). Similar mean $\mathrm{fO}_{2} \mathrm{~s}$ were obtained for the two meteorites; IW-3.1 \pm 0.2 for NWA 7325 and IW-2.8 \pm 0.2 for Y-791538.

\section{DISCUSSION}

Textural evidence suggests that olivine and pyroxene are early products of hightemperature equilibration with melt in NWA 7325 (Goodrich et al., 2014a) and Y-791538 (Goodrich et al., 2013). Both meteorites are inferred to have experienced a secondary event that affected mainly the pyroxene but not the olivine. In the case of NWA 7325, plagioclase was largely remelted and pyroxenes partially reacted with the melt (Bischoff et al., 2013, Goodrich et 
al., 2014a, Weber et al., 2016). This remelting was inferred by Bischoff et al. (2013) and Weber et al. (2016) to be due to contact metamorphism. However, Goodrich et al. (2014a) argued that it was more likely due to shock heating followed by excavation. Y-791538 experienced low to medium shock ("shock-smelting" or simultaneous melting and chemical reduction; see Warren and Rubin, 2010) affecting primarily the pyroxene. Thus, a comparison of valences in olivine is most likely to lead to constraints on the redox conditions during initial crystallization for both igneous rocks. In addition, the valence-specific partitioning behavior of $\mathrm{Cr}$ in olivine is the best constrained, suggesting that the inferred $f_{2}$ sare more tightly constrained. Simultaneously documenting the valences in pyroxene may tell us the effects of these secondary events and whether significant perturbations to the redox chemistry resulted.

Despite the difference in Fe content of the olivine in the two meteorites (Fo 91.3 vs 97.5 for Y-791538 and NWA 7325, respectively), the valences of each element $(\mathrm{Cr}, \mathrm{Ti}$, and $\mathrm{V})$ are similar for the two rocks (Figure 8), evidence that the redox conditions of olivine crystallization were similar for the two. All three elements are highly reduced in these olivine grains with substantial fractions of (NWA 7325 and Y-791538, respectively) $\mathrm{Cr}^{2+}(0.92 \pm 0.01,0.90 \pm 0.02)$, $\mathrm{Ti}^{3+}(0.53 \pm 0.02,0.64 \pm 0.03)$ and $\mathrm{V}^{2+}(0.58 \pm 0.02,0.52 \pm 0.02)$.

The pyroxene valences can also be informative of early crystallization conditions, but are more susceptible to overprinting during shock events. We observe that cpx and opx in Y-791538 yielded similar valences. Cr valences are similar to those in olivine $(\sim 2.1)$ whereas $\mathrm{Ti}$ and $\mathrm{V}$ valences were slightly more oxidized than those valences in olivine, i.e., $3.66 \pm 0.03$ vs. $3.36 \pm$ 0.03 for Ti and $2.65 \pm 0.02$ vs. $2.48 \pm 0.02$ for $\mathrm{V}$. In NWA 7325 , the valence relationships are similar for $\mathrm{Ti}$ and $\mathrm{V}$ (being more oxidized than in olivine) but the $\mathrm{Cr}$ valence in cpx is much more oxidized than in the olivine, $2.69 \pm 0.01$ vs $2.08 \pm 0.01$, and also much more oxidized than the pyroxenes of Y-791538 (2.69 \pm 0.01 vs $2.07 \pm 0.02)$.

The $\mathrm{Cr}, \mathrm{V}$, and Ti valences determined here for olivine and pyroxene in NWA 7325 and Y-791538 correspond to highly-reducing $f \mathrm{O}_{2}$ conditions well below IW (Figure 8) with the exception of $\mathrm{Cr}$ in NWA 7325 cpx. Mean $f \mathrm{O}_{2}$ values near IW-3 are indicated for both rocks (Figure 10). $\mathrm{Cr}$ in olivine is the best constrained in this approach and these results are IW-2.7 \pm 0.6 and IW- $2.4 \pm 0.6$, respectively, only $\sim 0.4$ more oxidized than the overall means, a difference that is comparable to the uncertainty. 
The general similarity of the $\mathrm{fO}_{2}$ results for NWA 7325 and the more-magnesian ureilites is consistent with the hypothesis that the NWA 7325 parent asteroid experienced a differentiation history similar to that of the ureilite parent body (Goodrich et al., 2014a). However, the results are also consistent with the oxidized endmember of modeling results for Mercury magmatism which suggest $f_{2}$ of IW-3 to -6 (McCubbin et al., 2012, Stockstill-Cahill et al., 2012). Thus, the XANES results alone do not allow us to rule out either an origin in a ureilite-like asteroid or an origin in Mercury.

Interestingly, the secondary events experienced by these two objects may have had the opposite effects on the inferred $\mathrm{fO}_{2}$ based on $\mathrm{Cr}$ valence in pyroxene. The olivine in the two rocks have similar $\mathrm{fO}_{2}(\sim \mathrm{IW}-2.5)$ but the $\mathrm{Cr}$ in pyroxene is more oxidized in NWA 7325 (IW+1) and more reduced in Y-981538 ( IW-5). Our data suggest that, in both cases, pyroxene may be more susceptible than olivine to valence overprinting, especially for Cr. Previous laboratory shock experiments in air have demonstrated shock oxidation of $\mathrm{Fe}$ in diopside without melting (e.g., McCanta et al., 2006).

In Y-791538, the secondary reduction event (shock smelting of pyroxenes) occurred in the presence of graphite and thus led to chemical reduction of the partly-melted pyroxene (e.g., Warren and Rubin, 2010). In this case, shock reheating in the presence of graphite led to the reduction of $\mathrm{Cr}$ in the pyroxene but negligible redox change to olivine cores.

In NWA 7325, the reheating was argued to be a shock event (Goodrich et al. 2014a). Textures supporting shock include precipitation of Ca-pyroxene wisps, veining, resorption textures (e.g., Bischoff et al., 2013, Goodrich et al., 2014a), shock lamellae in pyroxene and the mottled appearance of plagioclase (Goodrich et al., 2014a). In the absence of graphite, this shock event might lead to an oxidation of $\mathrm{Cr}$ in pyroxene and, as in the ureilite, negligible redox change to olivine cores. The $f_{2}$ indicated by $\mathrm{Cr}$ in NWA 7325 pyroxene $(\mathrm{IW}+1)$ is possibly a record of the conditions under which this shock event occurred, i.e., under more oxidizing conditions than the initial crystallization conditions, although the accuracy of applying a melt-crystal partitioning approach to shock events is questionable. The oxidized valences for plagioclase in NWA 7325 (Cr: $2.83 \pm 0.03$, Ti: $3.74 \pm 0.08$, and V: $3.35 \pm 0.02$ ), a phase that was also reset in this event, are consistent with this oxidation scenario. 
The scenario for oxidizing Cr in NWA 7325 pyroxene is problematic if this was a nearequilibrium process, as suggested by Bishop et al. (2014) and Weber et al. (2016), in which case the valences of $\mathrm{V}$ and $\mathrm{Ti}$ would also be expected to be oxidized. At the inferred $f \mathrm{O}_{2}$ of $\mathrm{IW}+1$, a significant fraction of $\mathrm{V}$ would be in the 4+ state and $\mathrm{Ti}$ would be nearly pure 4+; neither of these situations is observed. A similar situation exists in the reduction of $\mathrm{Cr}$ in $\mathrm{Y}-791538$ pyroxene in that $\mathrm{Ti}$ and $\mathrm{V}$ do not appear to be reduced compared to olivine. The absence of $\mathrm{V}$ and $\mathrm{Ti}$ redox change in these $\mathrm{Cr}$ redox modification events could be a kinetic effect. McCanta et al. (2006) showed that Fe in pyroxene (diopside) is oxidized when it is shocked at relatively high $\mathrm{pO}_{2}$. Crossed-polar images of their samples show shock lamellae similar to those in NWA 7325. We suggest that, in such a non-equilibrium process, $\mathrm{Cr}$ valence is more readily re-equilibrated than $\mathrm{Ti}$ and $\mathrm{V}$. Sluggishness of $\mathrm{Ti}^{3+}$ oxidation has been suspected in olivine from carbonaceous chondrites where $\mathrm{Ti}^{3+}$ is observed to co-exist with $\mathrm{FeO}$ (Simon et al., 2010).

An alternative explanation is that the secondary reheating process resulted in the resorption of a minor phase in the pyroxene that was enriched in $\mathrm{Cr}^{3+}$ but low in total $\mathrm{V}$ and Ti. Chromite and/or Cr-rich troilite would fit this bill and some such inclusions are still present in the meteorite. The $\mathrm{Cr}$ content of cpx is presently $0.17 \%$ (expressed as $\mathrm{Cr}_{2} \mathrm{O}_{3}$ ), an amount that could be contributed by $<1 \%$ chromite in cpx. Plagioclase, which was also modified/melted, also contains oxidized $\mathrm{Cr}$ (valence $=2.83 \pm 0.03$ ). The observation that the majority of the inclusions in cpx were dominated by $\mathrm{Cr}^{2+}$ would seem to rule outthis interpretation.

\section{CONCLUSIONS}

The $\mathrm{Ti}, \mathrm{Cr}$, and $\mathrm{V}$ valences in olivine and pyroxene are highly reduced and reasonably similar in the ungrouped achondrite NWA 7325 and ureilite Y-791538, with the main exception being more oxidized $\mathrm{Cr}$ in NWA 7325 pyroxene. $f \mathrm{O}_{2} \mathrm{~s}$ determined using the valences as proxies indicate reducing conditions near IW-3, a value that is consistent with origin of NWA 7325 in either a highly-reduced asteroid or Mercury. The XANES results alone do not allow either scenario to be ruled out but document the highly-reduced nature of the meteorites.

The oxidized $\mathrm{Cr}$ in NWA 7325 pyroxene is intriguing and may be due to a secondary reheating event (shock) that oxidized $\mathrm{Cr}$ in the pyroxene without similarly oxidizing $\mathrm{Ti}$ and $\mathrm{V}$. 
Such a separation of the redox couples may be an effect of re-equilibration kinetics, where the valence of $\mathrm{Cr}$ would be more rapidly modified.

The combination of $\mathrm{Ti}, \mathrm{V}$ and $\mathrm{Cr}$ valence and oxybarometric determinations is a powerful approach to constraining the histories of igneous materials and has the potential for identifying the presence of significant secondary events, such as shock metamorphism. Accuracy of the $f \mathrm{O}_{2}$ determinations hinges heavily on the availability of valence-specific partitioning data from controlled laboratory experiments, results that are currently sparse and need additional attention in future work.

\section{Acknowledgements}

We are grateful to P. Beck, P. King, J. Karner and an anonymous reviewer for thoughtful comments that improved this manuscript. This work was partly supported by NASA grant NNX12AH74G to Cyrena Goodrich and the Lunar and Planetary Institute. Authors acknowledge Brian Hess for the preparation of polished thin section and epoxy mount of NWA 7325. We thank M. Newville and A. Lanzirotti (University of Chicago) and W. Rao (University of Kentucky) for beamline assistance. Portions of this work were performed at Beamline X26A, National Synchrotron Light Source (NSLS), Brookhaven National Laboratory. X26A is supported by the Department of Energy (DOE) - Geosciences (DE-FG02-92ER14244 to The University of Chicago - CARS). Use of the NSLS was supported by DOE under Contract No. DE-AC02-98CH10886. Portions of this work were performed at GeoSoilEnviroCARS (Sector 13), Advanced Photon Source (APS), Argonne National Laboratory. GeoSoilEnviroCARS is supported by the National Science Foundation - Earth Sciences (EAR-1128799) and Department of Energy- Geosciences (DE-FG02-94ER14466). This research used resources of the Advanced Photon Source, a U.S. Department of Energy (DOE) Office of Science User Facility operated for the DOE Office of Science by Argonne National Laboratory under Contract No. DE-AC0206CH11357. We thank Mike Jercinovic for assistance in the electron microbeam facility at the University of Massachusetts. We are grateful to B. Hanson, J. Jones and G. Rossman for making the experimental standards available. 


\section{REFERENCES}

Angel R. J., Gasparik T. and Finger L. W. (1988) Crystal structure of a $\mathrm{Cr}^{2+}$-bearing pyroxene. Am. Mineral. 75(5), 599-603.

Barrat J. A., Greenwood R. C., Verchovsky A. B., Gillet Ph., Bollinger C., Langlade J. A., Liorzou C., and Franchi I. A. (2015) Crustal differentiation in the early solar system: Clues from the unique achondrite Northwest Africa 7325 (NWA 7325). Geochim. Cosmochim. Acta 168, 280-292.

Beckett J. R. (1986) The origin of calcium-, aluminum-rich inclusions from carbonaceous chondrites: an experimental study. Ph.D. Thesis, University of Chicago.

Berry A. J. and O'Neill H. S. C. (2004) A XANES determination of the oxidation state of chromium in silicate glasses. Am. Mineral. 89 (5-6), 790-798.

Berry A. J., O’Neill H. S. C., Scott D. R., Foran G. J., Shelley J. M. G. (2006) The effect of composition on $\mathrm{Cr}^{2+} / \mathrm{Cr}^{3+}$ in silicate melts. Am. Min. 91, 1901-1908.

Bischoff A., Ward D., Weber I., Morlok A., Hiesinger H. and Helbert J. (2013) NWA 7325 - not a typical olivine gabbro, but a rock that experienced fast cooling after a second (partial) melting event. Eur. Planet. Sci. Cong. Abstracts 8, \#427 (abstr.).

Dowty E. and Clark J. R. (1973) Crystal structure refinement and optical properties of a $\mathrm{Ti}^{3+}$ fassaite from the Allende meteorite. Am. Mineral. 58, 230-242.

Farges F., Brown Jr. G. E. and Rehr J. J. (1997) Ti K-edge XANES studies of Ti coordination and disorder in oxide compounds: Comparison between theory and experiment. Physical Review B 56, 1809-1819.

Goodrich C. A., Sutton S. R., Wirick S. and Jercinovic M. J. (2013) Chromium valences in ureilite olivine and implications for ureilite petrogenesis. Geochim. Cosmochim. Acta 122, 280-335.

Goodrich C. A., Kita N. T. and Nakashima D. (2014a) Petrology of the NWA 7325 ungrouped achondrite - meteorite from Mercury, the ureilite parent body, or a previously unsampled asteroid? In 45th Lunar and Planet. Sci. Conf., \#1246 (abstr.). 
Goodrich, C. A., Harlow G. E., Van Orman J. A., Sutton S. R., Jercinovic M. J., and Mikouchi T. (2014b) Petrology of chromite in ureilites: Implications for primary petrogenesis and secondary processes. Geochim. Cosmochim. Acta 135, 126-169.

Hanson B. and Jones J. H. (1998) The systematics of $\mathrm{Cr}^{3+}$ and $\mathrm{Cr}^{2+}$ partitioning between olivine and liquid in the presence of spinel. Am. Mineral. 83, 669-684.

Irving A. J., Kuehner S. M., Bunch T. E., Ziegler K., Chen G., Herd C. D. K., Conrey R. M., and Ralew S. (2013) Ungrouped mafic achondrite Northwest Africa 7325: A reduced, iron-poor cumulate olivine gabbro from a differentiated planetary parent body. Lunar Planet. Sci. XLIV, \#2164 (abstr.).

Karner J. M., Sutton S. R., Papike J. J., Shearer C. K., Jones J. H. and Newville M. (2006) Application of a new vanadium valence oxybarometer to basaltic glasses from the Earth, Moon and Mars. Am. Mineral. 91, 270-277.

Karner J. M., Papike J. J., Shearer C. K., McKay G., Le L. and Burger P. (2007a) Valence state portioning of $\mathrm{Cr}$ and $\mathrm{V}$ between pyroxene-melt: Estimates of oxygen fugacity for martian basalt QUE 94201. Am. Mineral. 92, 1238-1241.

Karner J. M., Papike J. J., Sutton S. R., Shearer C. K., McKay G., Le L., and Burger P. (2007b) Valence state partitioning of $\mathrm{Cr}$ between pyroxene-melt: Effects of pyroxene and melt composition and direct determination of $\mathrm{Cr}$ valence state by XANES. Application to martian basalt QUE 94201 composition. Am. Mineral. 92 (11-12), 2002-2005.

Karner J. M., Papike J. J., Sutton S. R., Shearer C. K., Burger P., McKay G. and Le L. (2008) Valence state partitioning of $\mathrm{V}$ between pyroxene-melt: Effects of pyroxene and melt composition, and direct determination of $\mathrm{V}$ valence states by XANES. Application to Martian basalt QUE 94201 composition. Meteoritics \& Planetary Science 43, 1275-1285.

Köhler T. P. and Brey G. P. (1990) Calcium exchange between olivine and clinopyroxene calibrated as a geothermobarometer for natural peridotites from 2 to $60 \mathrm{~kb}$ with applications. Geochimica et Cosmochimica Acta 54, 2375-2388.

Lombard P., Boizet B., Ollier N., Jouin A. and Yoshikawa A. (2009) Spectroscopic studies of $\mathrm{Ti}^{3+}$ ions speciation inside $\mathrm{MgAl}_{2} \mathrm{O}_{4}$ spinels. Journal of Crystal Growth 311, 899-903.

McCanta M. C., Dyar M. D. and Hörz F. P. (2006) Shock oxidation of pyroxene: Effects on redox ratio. Lunar Planet. Sci. XXXVII, \#1903 (abstr.). 
McCubbin F. M., Riner M. A., Vander Kaaden K. E. and Burkemper L. K. (2012) Is Mercury a volatile-rich planet? Geophys. Res. Lett. 39, L09202.

Papike J. J., Karner J. M. and Shearer C. K. (2005) Comparative planetary mineralogy: Valence state partitioning of $\mathrm{Cr}, \mathrm{Fe}$, Ti and $\mathrm{V}$ among crystallographic sites in olivine, pyroxene, and spinel from planetary basalts. Am. Mineral. 90, 277-290.

Papike J. J., Burger P. V., Bell A. S., Le L., Shearer C. K., Sutton S. R., Jones J. and Newville M. (2013) Developing vanadium valence state oxybarometers (spinel-melt, olivine-melt, spinel-olivine) and $\mathrm{V} /(\mathrm{Cr}+\mathrm{Al})$ partitioning (spinel-melt) for martian olivine-spinel basalts. Am. Mineral. 98, 2193-2196.

Papike J. J., Simon S. B., Burger P. V., Bell A. S., Shearer C. K., and Karner J. M. (2016) Chromium, vanadium, and titanium valence systematics in Solar System pyroxene as a recorder of oxygen fugacity, planetary provenance, and processes. Am. Mineral. 101, 907918.

Paque J. M., Sutton S. R., Simon S. B., Beckett J. R., Burnett D. S., Grossman L., Yurimoto H., Itoh S., Stolper E. M., Connolly Jr. H. C. (2013) XANES and Mg isotopic analyses of spinels in Ca-Al-rich inclusions: Evidence for formation under oxidizing conditions. Meteoritics \& Planetary Science 48, 2015-2043.

Prewitt C. T., Shannon R. D. and White W. B. (1972) Synthesis of a pyroxene containing trivalent titanium. Contrib. Mineral. Petr. 35, 77-82.

Righter K., Sutton S. R., Newville M., Le L., Schwandt C. S., Uchida H., Lavina B. and Downs R. T. (2006) An experimental study of the oxidation state of vanadium in spinel and basaltic melt with implications for the origin of planetary basalt. Am. Mineral. 91, 1643-1656.

Righter K., Sutton S., Danielson L., Pando K., Schmidt G., Yang H., Berthet S., Newville M., Choi Y., Downs R. T. and Malavergne V. (2011) The effect of $f \mathrm{O}_{2}$ on the partitioning and valence of $\mathrm{V}$ and $\mathrm{Cr}$ in garnet/melt pairs and the relation to terrestrial mantle $\mathrm{V}$ and $\mathrm{Cr}$ content. Am. Mineral. 96(8), 1278-1290.

Scheetz B. E. and White W. B. (1972) Synthesis and optical absorption spectra of $\mathrm{Cr}^{2+}-$ containing orthosilicates. Contr. Mineral. Petrol. 37, 221-227.

Schreiber H. D. (1986) Redox processes in glass-forming melts. Jour. Non-Crystalline Solids 84, $129-141$. 
Schreiber H. D. and Balazs G. B. (1982) Vanadium as an oxygen geobarometer in basaltic magmas: The further development of a geochemical electromotive force series in silicate melts. Lunar and Planetary Science XIII, 692-693.

Simon S. B., Grossman L. and Davis A. M. (1991) Fassaite composition trends during crystallization of Allende Type B refractory inclusion melts. Geochim. Cosmochim. Acta 55, 2615-2655.

Simon S. B., Sutton S. R., and Grossman L. (2007) Valence of Ti and V in pyroxene in refractory inclusion interiors and rims. Geochimica et Cosmochimica Acta 71, 3098-3118.

Simon S. B., Sutton S. R. and Grossman L. (2008) Constraints on the oxidation state of chondrule precursors from titanium XANES analysis of Semarkona chondrules. Lunar Planet. Sci. XXXIX, Lunar and Planetary Institute, Houston, TX, \#1352 (abstr.).

Simon S. B., Sutton S. R. and Grossman L. (2009) First Ti-XANES analyses of refractory inclusions from Murchison. Lunar Planet. Sci. XL, Lunar and Planetary Institute, Houston, TX, \#1626 (abstr.).

Simon S. B., Sutton S. R., and Grossman L. (2010) First Ti-XANES analyses of olivine in amoeboid olivine aggregates. $73^{\text {rd }}$ Annual Met. Soc. Meeting, New York, \#5123 (abstr.).

Simon S. B., Beckett J. R., Sutton S. R. and Grossman L. (2014) Experimental investigation of Ti And Fe valence in chondrule-like melts during cooling under changing Redox conditions at low partial pressures. Lunar Planet. Sci. XLV, Lunar and Planetary Institute, Houston, TX, \#1633 (abstr.).

Simon, S. B., Sutton S. R., and Grossman L. (2016) The Valence and Coordination of Ti in Ordinary and Enstatite Chondrites. Geochim. Cosmochim. Acta 189, 377-390.

Stockstill-Cahill K. R., McCoy T. J., Nittler L. R., Weider S. Z. and Hauck II S. A. (2012) Magnesium-rich crustal compositions on Mercury: Implications for magmatism from petrologic modeling. Journal of Geophysical Research 117, E00L15.

Sutton S. R., Jones K. W., Gordon B., Rivers M. L. and Smith J. V. (1993) Reduced chromium in olivine grains from lunar basalt 15555: X-ray absorption near edge structure (XANES). Geochim. Cosmochim. Acta 57-2, 461-468.

Sutton S. R., Bertsch P. M., Newville M., Rivers M., Lanzirotti A. and Eng P. (2002) Microfluorescence and microtomography analyses of heterogeneous earth and environmental materials, Reviews in Mineralogy \& Geochemistry: Applications of 
Synchrotron Radiation in Low-Temperature \& Environmental Science 49, Mineralogical Society of America, 429-483.

Sutton S. R., Karner J. M., Delaney J. S., Papike J. J., Shearer C. K., Newville M., Rivers M., Eng P. and Dyar M. D. (2005) Vanadium K edge XANES of synthetic and natural basaltic glasses and application to microscale oxygen barometry. Geochim. Cosmochim. Acta 69/9, 2333-2348.

Takeda H. (1989) Mineralogy of coexisting pyroxenes in magnesian ureilites and their formation conditions. Earth and Planetary Science Letters 93, 181-194.

Tribaudino M. (2006) Microtextures and crystal chemistry of pigeonite in the ureilites ALHA77257, RKPA80239, Y-791538, and ALHA81101. Meteoritics \& Planetary Science 41, 979-988.

Warren P. H., and Rubin A. E. (2010) Pyroxene-selective impact smelting in ureilites. Geochim. Cosmochim. Acta 74, 5109-5133.

Waychunas G.A. (1987) Synchrotron radiation XANES spectroscopy of Ti in minerals: Effects of Ti bonding distances, Ti valence and site geometry on absorption edge structure. Am. Mineral. 72, 89-101.

Weber I., Morlok A., Bischoff A., Hiesinger H., Ward D., Joy K. H., Crowther S. A., Jastrzebski N. D., Gilmour J. D., Clay P. L., Wogelius R. A., Greenwood R. C., Franchi I. A. and Münker C. (2016) Cosmochemical and spectroscopic properties of Northwest Africa 7325 A consortium study. Meteorit. Planet. Sci. 51, 3-30.

Weider S. Z., Nittler L. R., Starr R. D., McCoy T. J., Stockstill-Cahill K. R., Byrne P. K., Denevi B. W., Head J. W. and Solomon S. C. (2012) Chemical heterogeneity on Mercury's surface revealed by the MESSENGER X-ray Spectrometer. Journal of Geophysical Research 117, E00L05

Wong J., Lytle F. W., Messmer R. P. and Maylotte D. H. (1984) K-edge absorption spectra of selected vanadium compounds. Phys. Rev. B 30, 5596-5610. 


\section{Figure Captions}

Figure 1: Backscattered electron image of the NWA 7325 thin section showing the locations of the olivine (yellow labels), pyroxene (white labels), and plagioclase (orange) grains for XANES analysis. Bright inclusions are typically sulfide or rare metal.

Figure 2: Backscattered electron image of the Y-791538 thin section showing the locations of olivine (yellow labels) and pyroxene (white labels; PIG=pigeonite, OPX=orthopyroxene) grains for XANES analysis. The bright veins are metal or terrestrial iron oxides (altered metal; Goodrich et al. 2014b).

Figure 3: Ti XANES systematics. a) Ti K XANES pre-edge peaks for standards: Synthetic forsterite, high intensity, low centroid energy for $\mathrm{Ti}^{4+}$ (tetrahedral); natural acmite, low intensity, high centroid energy for $\mathrm{Ti}^{4+}$ (octahedral); and synthetic acmite, low intensity, low centroid energy for $\mathrm{Ti}^{3+}$ (octahedral). b) The centroids and intensities of these three measured spectra form the calibration field from which proportions of the three components are extracted using the lever rule. The non-linear mixing curve between tetrahedral and octahedral $\mathrm{Ti}^{4+}$ (red filled circles connected by linear joining segments) was determined empirically by computationally mixing the two measured end-member spectra in different proportions and processing the resulting synthetic spectra as unknowns.

Figure 4: V XANES systematics: a) Representative spectra for Schreiber calibration glasses showing the dramatic correlation between pre-edge peak intensity and valence. b) Valence calibration curve for pre-edge peak intensity versus known $\mathrm{V}$ valence (by spectrophotometry) for the Schreiber glasses. From Sutton et al. (2005).

Figure 5: Cr K XANES systematics: a) Spectra for CMAS glass standards (Hanson and Jones, 1998); $\mathrm{Cr}^{2+}$ standard (blue; sealed graphite) and $\mathrm{Cr}^{3+}$ standard (red; $\mathrm{CO}_{2}$ ). The reduced species shows an absorption edge at lower energy than the oxidized one. $\mathrm{Cr}$ valence is based on the intensity of the prominent bump on the $\mathrm{Cr}^{2+}$ absorption edge (arrow). b) $\mathrm{The}^{2+}{ }^{2+}$ peak intensity is determined from the height of the $\sim 5995 \mathrm{eV}$ peak in the normalized derivative spectrum.

Figure 6: Comparison of olivine and pyroxene derivative $\mathrm{Cr} \mathrm{K}$ XANES spectra for $\mathrm{Cr}^{2+}$ (a; olivine and pyroxene from ureilites PCA82506) and $\mathrm{Cr}^{3+}$ (b; synthetic forsterite, San Carlos cpx) 
standard endmembers. These results show that the $1 \mathrm{~s}-4 \mathrm{~s}$ peak in both olivine and pyroxene (labeled "OL" and "PX", respectively) moves to higher energy by $\sim 2.8 \mathrm{eV}$ in going from $\mathrm{Cr}^{2+}$ to $\mathrm{Cr}^{3+}$. The difference in energy between the two phases at a given valence is $\sim 1.1 \mathrm{eV}$. Vertical lines are provided to guide the eye in comparing the energies of the peaks.

Figure 7: Representative XANES spectra for $\mathrm{Ti}, \mathrm{Cr}$ and $\mathrm{V}$ in olivine, pyroxene and plagioclase (orientation merges for $\mathrm{Cr}$ ).

Figure 8: Summary of $\mathrm{Ti}(\mathrm{a}), \mathrm{Cr}(\mathrm{b})$, and $\mathrm{V}$ (c) valences obtained for olivine (OL), pyroxene (CPX and OPX) and plagioclase (PLAG) in NWA 7325 and Y-791538. Error bars (standard error of the mean) are shown and are typically comparable to or smaller than the symbol size. Results are dispersed horizontally and grouped by mineral type with the valences for the same mineral in the two meteorites offset horizontally for clarity. The valences are in good agreement between the two meteorites except for the $\mathrm{Cr}$ valence in pyroxene.

Figure 9: Valence $\left(F_{\text {crystal }}\right)$ vs. oxygen fugacity for olivine $(\mathrm{a}, \mathrm{b}, \mathrm{c})$ and pyroxene $(\mathrm{d}, \mathrm{e}, \mathrm{f})$ based on equation 2 and applying valence-specific partition coefficient ratios (see text). A calibration line applicable to both NWA 7325 and Y-791538 is shown for each of the three redox couples relevant in this work. Dashed lines represent $1 \sigma$ uncertainty levels. Valence-specific partition coefficient ratios used were slightly different for $\mathrm{Cr}$ in olivine in the two samples (Table 3) but the resulting calibration lines are indistinguishable on this plot.

Figure 10: Oxygen fugacity summary for NWA 7325 (a) and Y-791538 (b) based on Ti, V, and $\mathrm{Cr}$ valences in olivine and pyroxene. Also shown are overall weighted mean values ( horizontal bar with height indicating uncertainty level, $1 \sigma$ ) for each meteorite; the $\mathrm{Cr}$ results for pyroxene have been omitted from the weighted mean calculations (see text). 
Table 1: NWA 7325: Valence results for olivine, pyroxene and plagioclase. Mean valences are the error-weighted means of all valence results for a given mineral. Values in parentheses are $1 \sigma$ uncertainties in the rightmost digit(s). Errors for mean valences are standard errors of the means $(1 \sigma$; see text). Blank fields indicate where no data were obtained. "Tet $(\%)$ " is the percent of Ti in tetrahedral coordination. $+=\mathrm{Cr}$ measurements from NSLS X26A; valence results for each grain are determined by merging spectra at different orientations (see text).

NWA7325

\begin{tabular}{|c|c|c|c|c|c|}
\hline & Grain & $\mathrm{Cr}$ & $\mathrm{Ti}$ & $\begin{array}{l}\text { Tet } \\
\text { (\%) }\end{array}$ & $\mathbf{v}$ \\
\hline \multirow[t]{25}{*}{$\mathrm{OL}$} & OL1+ & $2.17(5)$ & & & \\
\hline & OL2a+ & $2.17(5)$ & & & \\
\hline & $\mathrm{OL} 2 \mathrm{~b}+$ & $2.15(5)$ & & & \\
\hline & OL3+ & $2.14(5)$ & & & \\
\hline & OL4+ & $2.11(5)$ & & & \\
\hline & OL5+ & $2.10(5)$ & $3.35(5)$ & $0(1)$ & \\
\hline & OL6 & $2.15(5)$ & $3.26(6)$ & $13(1)$ & \\
\hline & OL6a+ & $2.10(5)$ & & & $2.49(5)$ \\
\hline & OL6b+ & $2.05(5)$ & & & $2.44(5)$ \\
\hline & OL7 & $2.14(5)$ & $3.45(7)$ & $16(2)$ & $2.41(5)$ \\
\hline & $\mathrm{OL7+}$ & $2.16(5)$ & & & \\
\hline & OL8 & $1.96(5)$ & $3.50(6)$ & $9(1)$ & $2.43(5)$ \\
\hline & OL8a+ & $2.07(5)$ & & & \\
\hline & $\mathrm{OL} 8 \mathrm{~b}+$ & $2.11(5)$ & & & \\
\hline & OL9+ & $2.09(5)$ & $3.58(6)$ & $13(1)$ & \\
\hline & OL10a+ & $2.16(5)$ & & & \\
\hline & OL10b+ & $2.06(5)$ & & & \\
\hline & OL11 & $1.84(5)$ & $3.52(7)$ & $15(2)$ & $2.40(5)$ \\
\hline & OL11+ & $2.18(5)$ & & & \\
\hline & OL12+ & $2.10(5)$ & & & \\
\hline & OL13 & $2.08(5)$ & $3.74(7)$ & $9(1)$ & $2.37(5)$ \\
\hline & OL13+ & $2.10(5)$ & & & \\
\hline & OL14 & $1.84(5)$ & & & \\
\hline & OL15 & $2.01(5)$ & & & \\
\hline & mean & $2.08(1)$ & $3.47(2)$ & $13(1)$ & $2.42(2)$ \\
\hline \multirow[t]{4}{*}{ CPX } & PX1+ & $2.75(5)$ & & & \\
\hline & PX1a & $2.66(5)$ & $3.87(9)$ & $32(2)$ & $2.70(5)$ \\
\hline & $\mathrm{PX} 2+$ & $2.63(5)$ & & & \\
\hline & PX3+ & $2.61(5)$ & & & \\
\hline
\end{tabular}




\begin{tabular}{|c|c|c|c|c|c|}
\hline & PX4+ & $2.62(5)$ & & & \\
\hline & PX5 & $2.71(5)$ & $3.86(10)$ & $35(2)$ & $2.63(5)$ \\
\hline & PX6 & $2.73(5)$ & $3.71(9)$ & $32(2)$ & $2.69(5)$ \\
\hline & PX7 & $2.63(5)$ & $3.52(7)$ & $22(2)$ & \\
\hline & PX8 & $2.73(5)$ & 3.77 (9) & $32(2)$ & $2.70(5)$ \\
\hline & PX9 & $2.74(5)$ & $3.82(9)$ & $32(2)$ & $2.62(5)$ \\
\hline & PX10 & $2.72(5)$ & $3.88(10)$ & $33(2)$ & $2.62(5)$ \\
\hline & PX11 & $2.75(5)$ & $3.67(8)$ & $30(2)$ & $2.69(5)$ \\
\hline & PX12 & $2.70(5)$ & $3.37(6)$ & $14(1)$ & \\
\hline & PX12A & & $3.45(6)$ & $13(1)$ & \\
\hline & PX13 & $2.72(5)$ & $3.78(9)$ & $33(2)$ & \\
\hline & PX14 & $2.66(5)$ & 3.74 (9) & $34(2)$ & \\
\hline & mean & 2.69 (1) & $3.64(2)$ & $26(1)$ & $2.66(2)$ \\
\hline Plag & Plag1 & $2.82(5)$ & 3.74 (9) & $35(2)$ & \\
\hline & Plag2 & $2.77(5)$ & & & $3.33(8)$ \\
\hline & Plag3 & $2.87(5)$ & & & $3.58(8)$ \\
\hline & Plag4 & $2.88(5)$ & & & $3.45(5)$ \\
\hline & Plag6 & & & & $3.29(5)$ \\
\hline & Plag7 & & & & $3.33(5)$ \\
\hline & Plag8 & & & & $3.26(5)$ \\
\hline & mean & $2.83(3)$ & 3.74 (9) & $35(2)$ & $3.35(2)$ \\
\hline
\end{tabular}


Table 2: Y-791538: Valence results for olivine, clinopyroxene and orthopyroxene. All Cr data from NSLS X26A; Ti and V data from GSECARS APS. Mean valences are the error-weighted means of all valence results for a given mineral. Values in parentheses are $1 \sigma$ uncertainties in the rightmost digit(s). Errors for mean valences are standard errors of the means $(1 \sigma$; see text). Blank fields indicate where no data were obtained. "Tet (\%)" is the percent of Ti in tetrahedral coordination.

Y791538

\begin{tabular}{|c|c|c|c|c|c|}
\hline & & $\mathrm{Cr}+$ & $\mathrm{Ti}$ & $\begin{array}{l}\text { Tet } \\
\text { (\%) }\end{array}$ & $\mathbf{v}$ \\
\hline \multirow[t]{8}{*}{ OL } & OL1 & $2.13(5)$ & $3.39(6)$ & $12(1)$ & $2.45(5)$ \\
\hline & OL2 & $2.12(5)$ & $3.46(6)$ & $10(1)$ & $2.43(5)$ \\
\hline & OL3 & $2.13(5)$ & $3.50(6)$ & $13(1)$ & $2.52(5)$ \\
\hline & OL4 & $2.11(5)$ & $3.38(7)$ & $15(1)$ & $2.52(5)$ \\
\hline & OL5 & $2.08(5)$ & $3.16(6)$ & $4(1)$ & 2.49 (5) \\
\hline & OL6 & $2.07(5)$ & & & \\
\hline & OL7 & 2.09 (5) & & & \\
\hline & mean & $2.10(2)$ & $3.36(3)$ & $11(1)$ & $2.48(2)$ \\
\hline \multirow[t]{6}{*}{ CPX } & PIG1 & $2.10(5)$ & 3.65 (10) & $41(3)$ & $2.63(5)$ \\
\hline & PIG2 & 2.10 (5) & 3.36 (7) & $25(2)$ & $2.54(5)$ \\
\hline & PIG3 & $1.96(5)$ & $3.90(12)$ & $45(3)$ & $2.75(5)$ \\
\hline & PIG4 & $2.09(5)$ & $3.89(13)$ & $47(3)$ & $2.68(5)$ \\
\hline & PIG5 & $2.06(5)$ & $4.04(13)$ & $50(3)$ & $2.71(5)$ \\
\hline & mean & $2.06(2)$ & $3.64(5)$ & $36(2)$ & $2.66(2)$ \\
\hline \multirow[t]{8}{*}{ OPX } & OPX1 & $2.02(5)$ & 4.03 (13) & $50(3)$ & $2.73(5)$ \\
\hline & OPX2 & $2.07(5)$ & $3.84(12)$ & $45(3)$ & $2.65(5)$ \\
\hline & OPX3 & $2.00(5)$ & & & \\
\hline & OPX4 & $2.07(5)$ & & & \\
\hline & OPX5 & $2.06(5)$ & $3.76(11)$ & $45(3)$ & $2.68(5)$ \\
\hline & OPX6 & $2.02(5)$ & $3.44(8)$ & $33(2)$ & $2.63(5)$ \\
\hline & OPX7 & $2.33(5)$ & 3.65 (10) & $38(3)$ & $2.57(5)$ \\
\hline & mean & $2.08(2)$ & $3.68(5)$ & $42(2)$ & $2.65(2)$ \\
\hline
\end{tabular}

+ Uses merging of spectra at different orientations for each grain. 
Table 3: Summary of Oxygen Fugacity Determinations

\begin{tabular}{|c|c|c|c|c|c|c|c|c|c|}
\hline & & \multicolumn{2}{|c|}{ Silicate } & \multirow{2}{*}{$\begin{array}{l}\text { Silicate/Melt } \\
\text { (Reduced)/ } \\
D(\text { Oxidized) }\end{array}$} & \multicolumn{5}{|c|}{ Calculated Melt } \\
\hline NWA 7325 & & Valence & $\begin{array}{l}\text { Reduced/ } \\
\text { Oxidized }\end{array}$ & & $\begin{array}{l}\text { Reduced/ } \\
\text { Oxidized }\end{array}$ & Valence & $\begin{array}{l}\log \mathrm{fO}_{2} \\
\text { relative to } \\
\text { equal } \\
\text { proportions }\end{array}$ & $\begin{array}{c}\Delta \text { IW of } \\
\text { equal } \\
\text { proportions }\end{array}$ & $\Delta \mathrm{IW}$ \\
\hline \multirow[t]{3}{*}{ Olivine } & $\mathrm{Ti}$ & $3.47(2)$ & $1.13(8)$ & $5.0(2.5)$ & $0.23(12)$ & $3.82(8)$ & $2.59(71)$ & $-7.0(5)$ & $-4.4(9)$ \\
\hline & v & $2.42(2)$ & $1.38(12)$ & $2(1)$ & $0.69(35)$ & $2.59(10)$ & $0.64(71)$ & $-3.0(5)$ & $-2.4(9)$ \\
\hline & $\mathrm{Cr}$ & $2.08(1)$ & $11.5(1.4)$ & $1.0(1)$ & $11.5(1.8)$ & $2.08(1)$ & $-4.24(26)$ & $1.5(5)$ & $-2.7(6)$ \\
\hline \multirow[t]{3}{*}{ CPX (diop) } & $\mathrm{Ti}$ & $3.64(2)$ & $0.56(4)$ & $3(1)$ & $0.19(6)$ & $3.84(4)$ & $2.91(53)$ & $-7.0(5)$ & $-4.1(7)$ \\
\hline & V & $2.66(2)$ & $0.52(5)$ & $1.0(5)$ & $0.52(26)$ & $2.66(10)$ & $1.15(73)$ & $-3.0(5)$ & $-1.8(9)$ \\
\hline & $\mathrm{Cr}$ & $2.69(1)$ & $0.45(2)$ & $0.3(1)$ & $1.5(5)$ & $2.4(7)$ & $-0.7(5)$ & $1.5(5)$ & $0.8(7)$ \\
\hline \multicolumn{3}{|c|}{ Olivine weighted mean } & & & & & & & $-3.1(3)$ \\
\hline \multicolumn{5}{|c|}{ Pyroxene weighted mean excluding $\mathrm{Cr}$ in $\mathrm{cpx}$} & & & & & $-3.1(4)$ \\
\hline \multicolumn{5}{|c|}{ Combined weighted mean excluding $\mathrm{Cr}$ in $\mathrm{cpx}$} & & & & & $-3.1(2)$ \\
\hline Y-791538 & & Valence & $\begin{array}{l}\text { Reduced/ } \\
\text { Oxidized }\end{array}$ & $\begin{array}{l}D(\text { Reduced }) / \\
D(\text { Oxidized })\end{array}$ & $\begin{array}{l}\text { Reduced/ } \\
\text { Oxidized }\end{array}$ & Valence & $\begin{array}{l}\log f^{\mathrm{O}_{2}} \\
\text { relative to } \\
\text { equal } \\
\text { proportions }\end{array}$ & $\begin{array}{c}\Delta \text { IW of } \\
\text { equal } \\
\text { proportions }\end{array}$ & $\Delta \mathrm{IW}$ \\
\hline \multirow[t]{3}{*}{ Olivine } & $\mathrm{Ti}$ & $3.36(3)$ & $1.78(22)$ & $5.0(2.5)$ & $0.36(19)$ & $3.74(9)$ & $1.79(74)$ & $-7.0(5)$ & $-5.2(9)$ \\
\hline & V & $2.48(2)$ & $1.07(7)$ & $2(1)$ & 0.54 (27) & $2.65(10)$ & $1.08(72)$ & $-3.0(5)$ & $-1.9(9)$ \\
\hline & $\mathrm{Cr}$ & $2.10(2)$ & $8.7(1.4)$ & $0.9(1)$ & $9.7(1.9)$ & $2.09(1)$ & $-3.95(29)$ & $1.5(5)$ & $-2.4(6)$ \\
\hline \multirow[t]{3}{*}{ CPX (pig) } & $\mathrm{Ti}$ & $3.64(5)$ & $0.56(9)$ & $3(1)$ & $0.19(7)$ & $3.84(5)$ & $2.91(57)$ & $-7.0(5)$ & $-4.1(8)$ \\
\hline & $\mathrm{V}$ & $2.66(2)$ & $0.51(4)$ & $1.0(5)$ & $0.51(26)$ & $2.66(9)$ & $1.17(65)$ & $-3.0(5)$ & $-1.8(8)$ \\
\hline & $\mathrm{Cr}$ & $2.06(2)$ & $15.7(4.2)$ & $0.3(1)$ & $53(23)$ & $2.02(1)$ & $-6.9(62)$ & $1.5(5)$ & $-5.4(8)$ \\
\hline \multirow[t]{3}{*}{ OPX (enst) } & $\mathrm{Ti}$ & $3.68(5)$ & $0.48(11)$ & $3(1)$ & $0.16(6)$ & $3.86(4)$ & $3.18(59)$ & $-7.0(5)$ & $-3.8(8)$ \\
\hline & V & $2.65(2)$ & $0.53(4)$ & $1.0(5)$ & $0.53(27)$ & $2.65(9)$ & $1.09(70)$ & $-3.0(5)$ & $-1.9(9)$ \\
\hline & $\mathrm{Cr}$ & $2.08(2)$ & $11.7(2.7)$ & $0.3(1)$ & $39(16)$ & $2.02(1)$ & $-6.37(59)$ & $1.5(5)$ & $-4.9(8)$ \\
\hline \multicolumn{3}{|c|}{ Olivine weighted mean } & & & & & & & $-2.7(2)$ \\
\hline \multicolumn{5}{|c|}{ Pyroxene weighted mean excluding $\mathrm{Cr}$ in $\mathrm{cpx}$ and opx } & & & & & $-2.9(3)$ \\
\hline \multicolumn{5}{|c|}{ Combined weighted mean excluding $\mathrm{Cr}$ in $\mathrm{cpx}$ and opx } & & & & & $-2.8(2)$ \\
\hline
\end{tabular}

Values in parentheses are $1 \sigma$ uncertainties in the rightmost digit(s). 

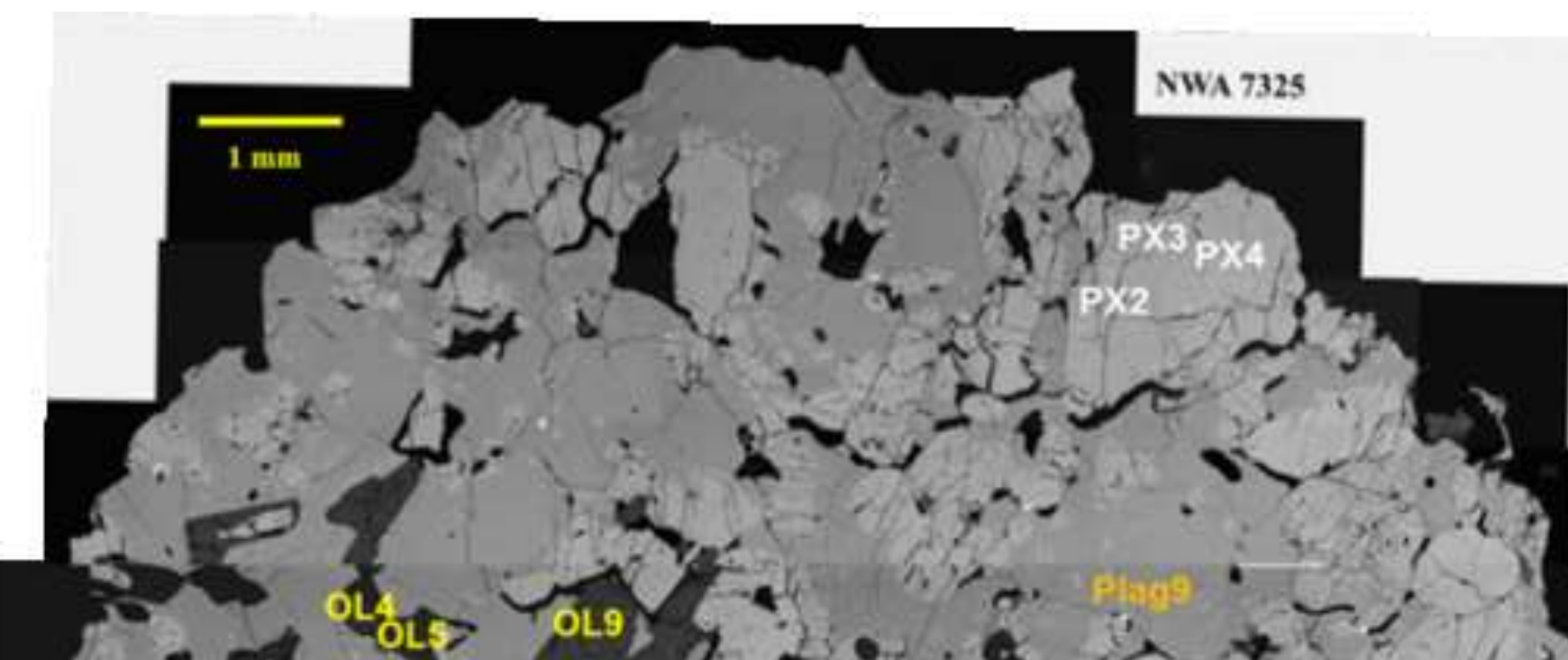

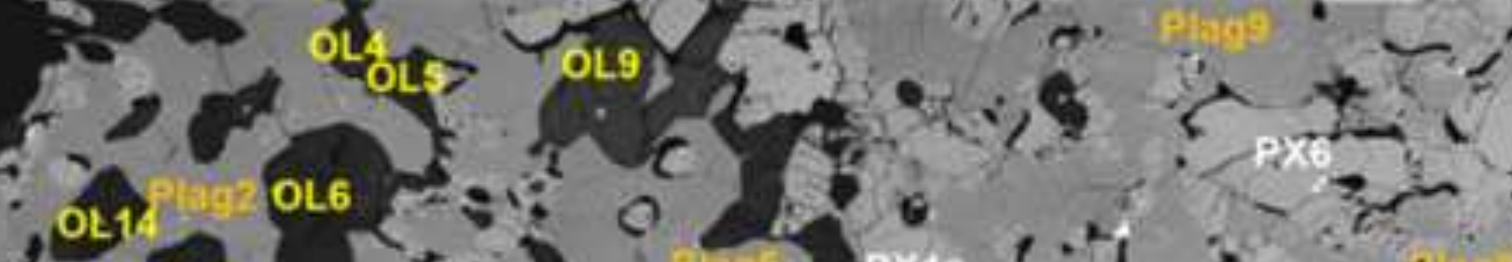

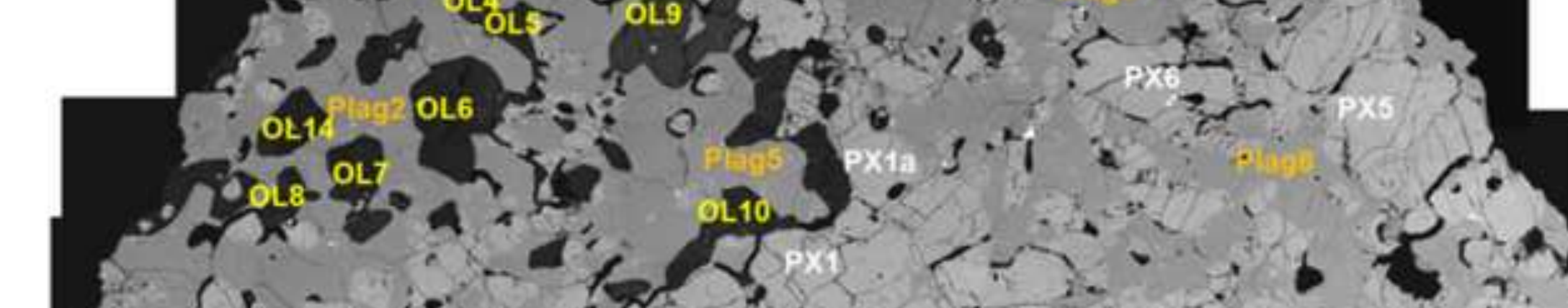

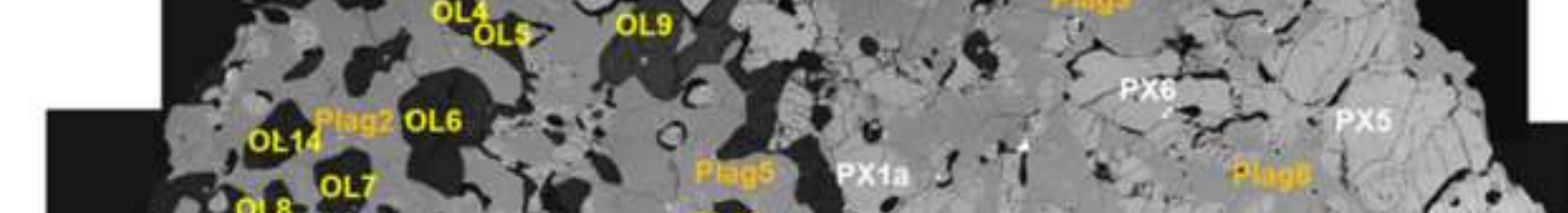

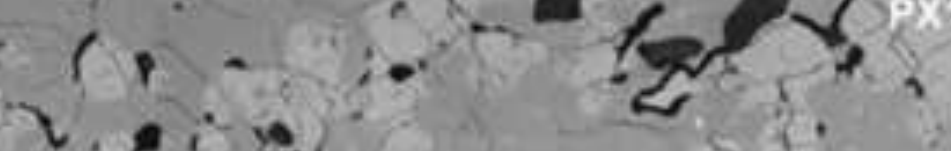

(2) is

c.

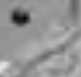

:1, 年 $x \frac{2}{2}$

C. $-6 \times 10^{\circ}$ PX9 $2 \times 96$ o

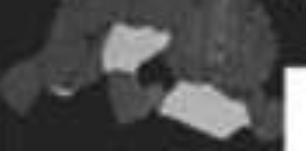

r.

rat . ? $\rightarrow$ 4 QL15 (2) 


\section{Y791538}

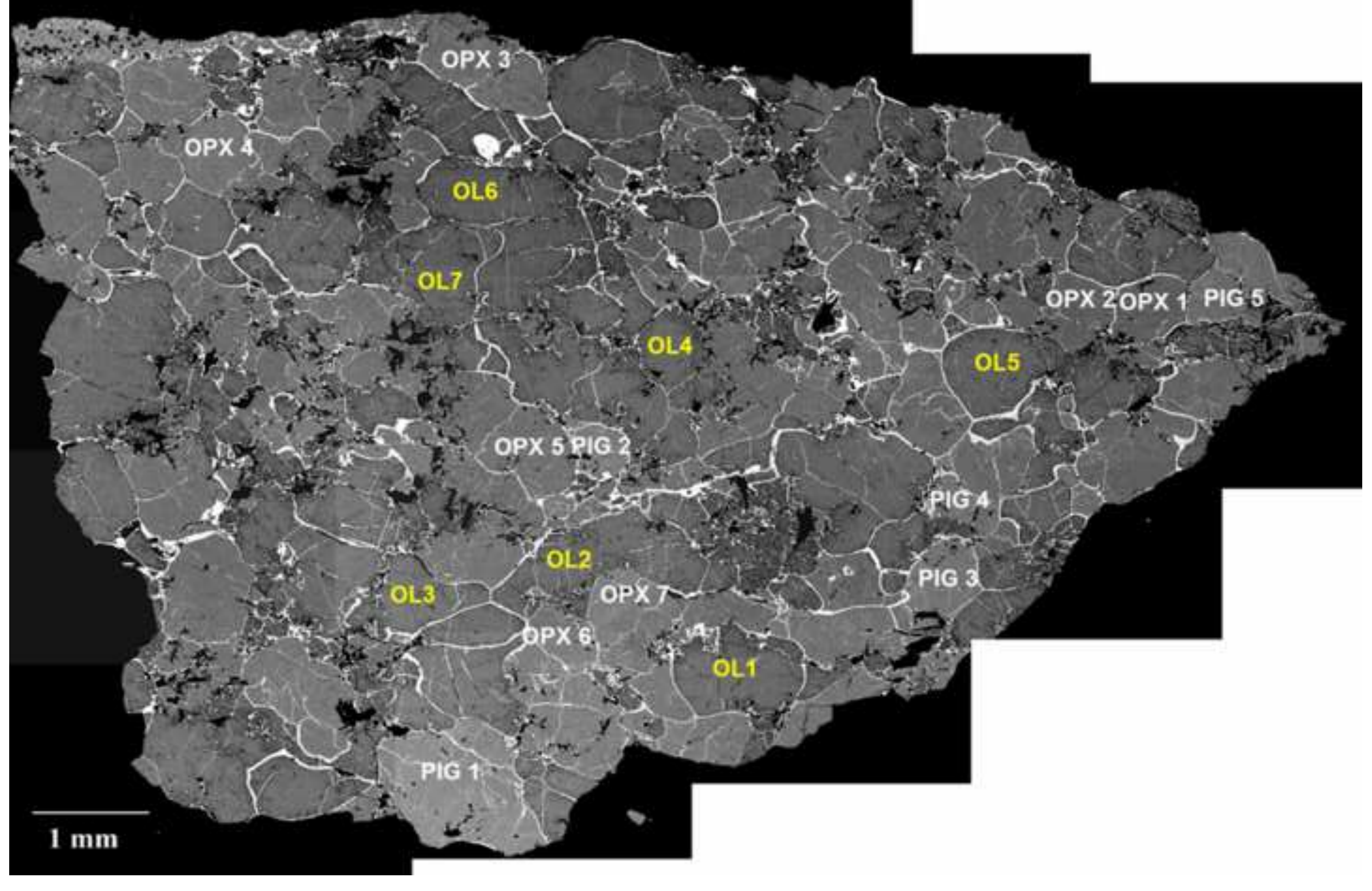




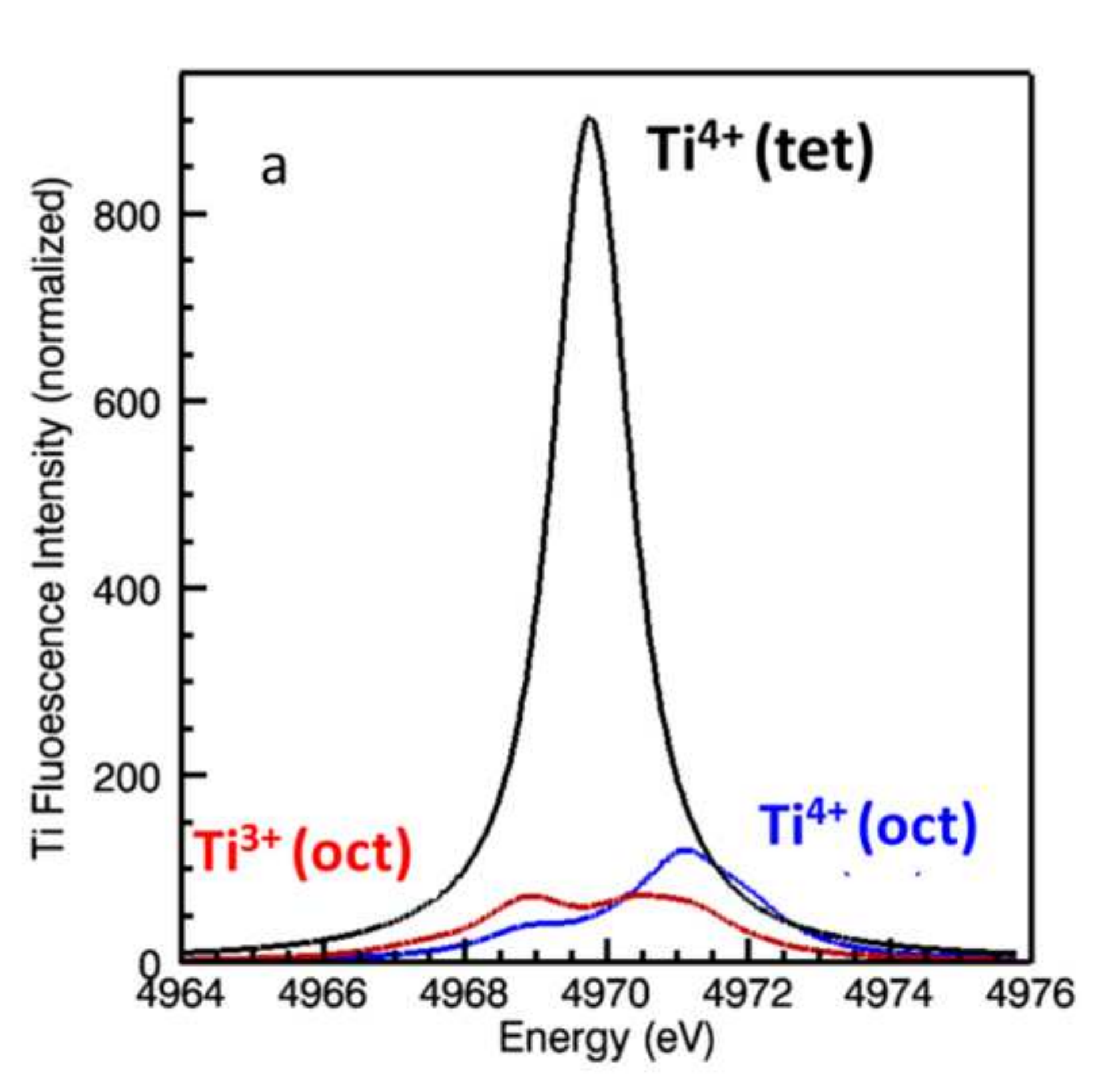

b

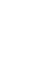

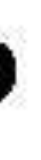




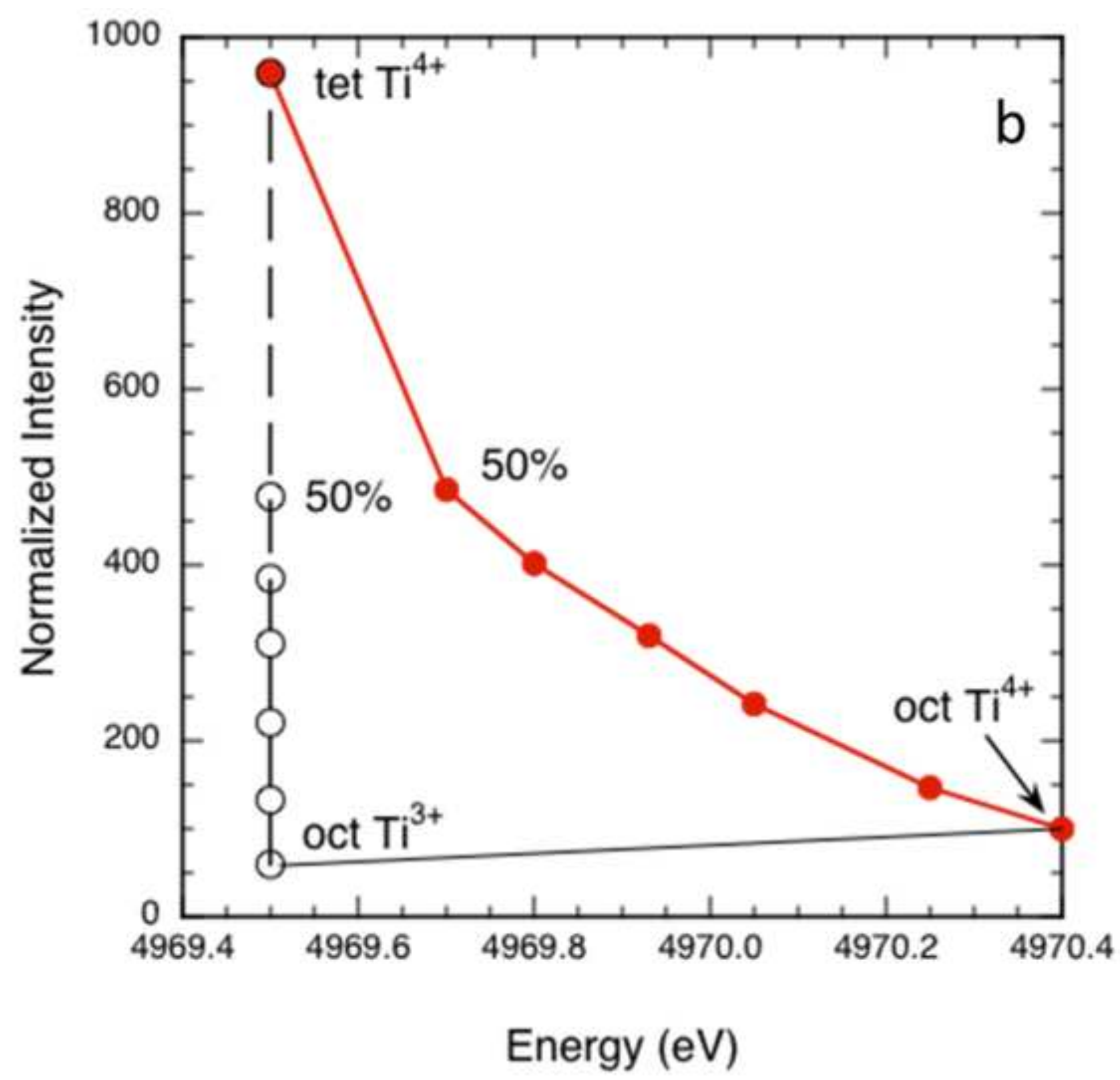

Energy (eV) 


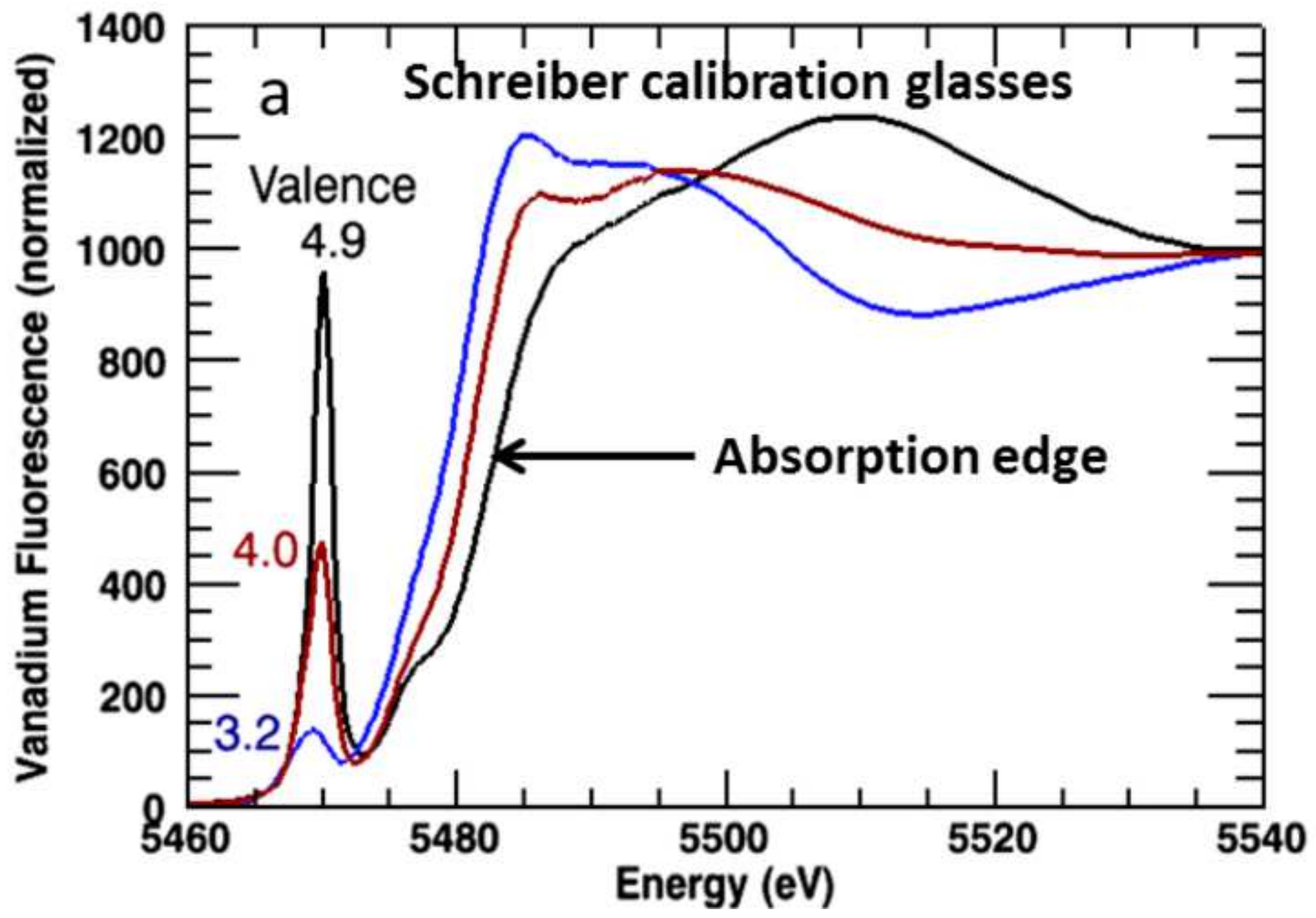



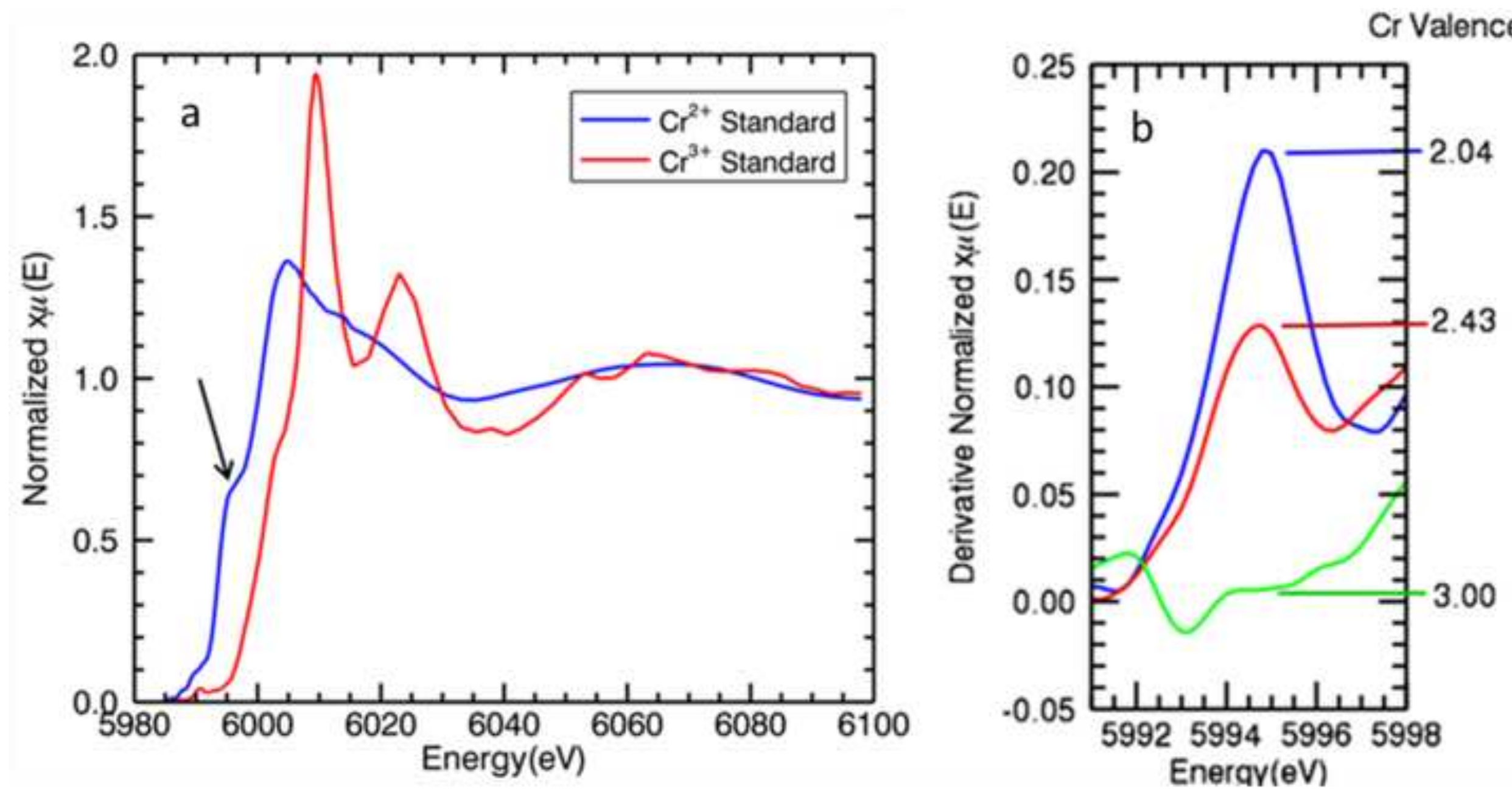

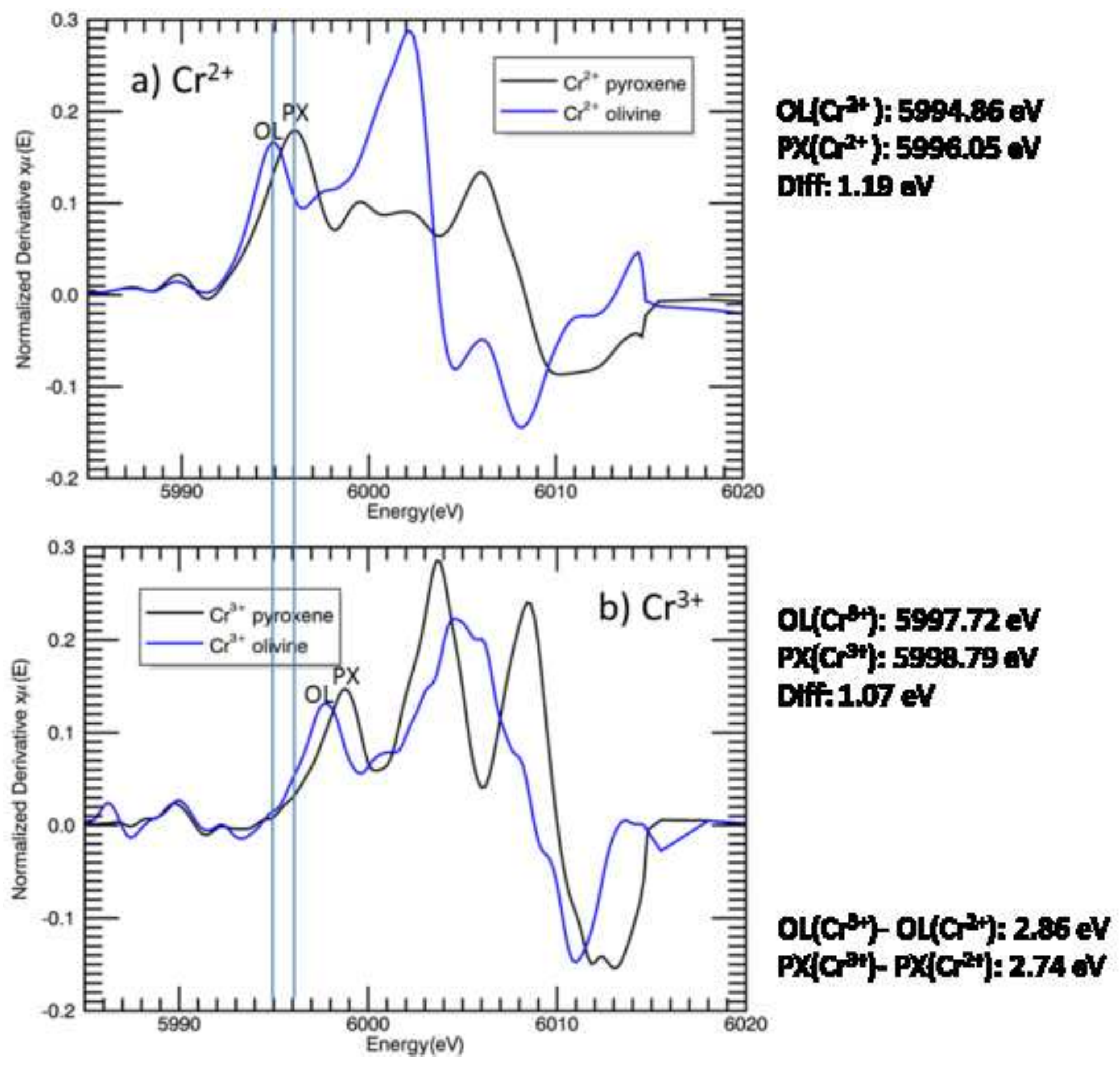
NWA 7325
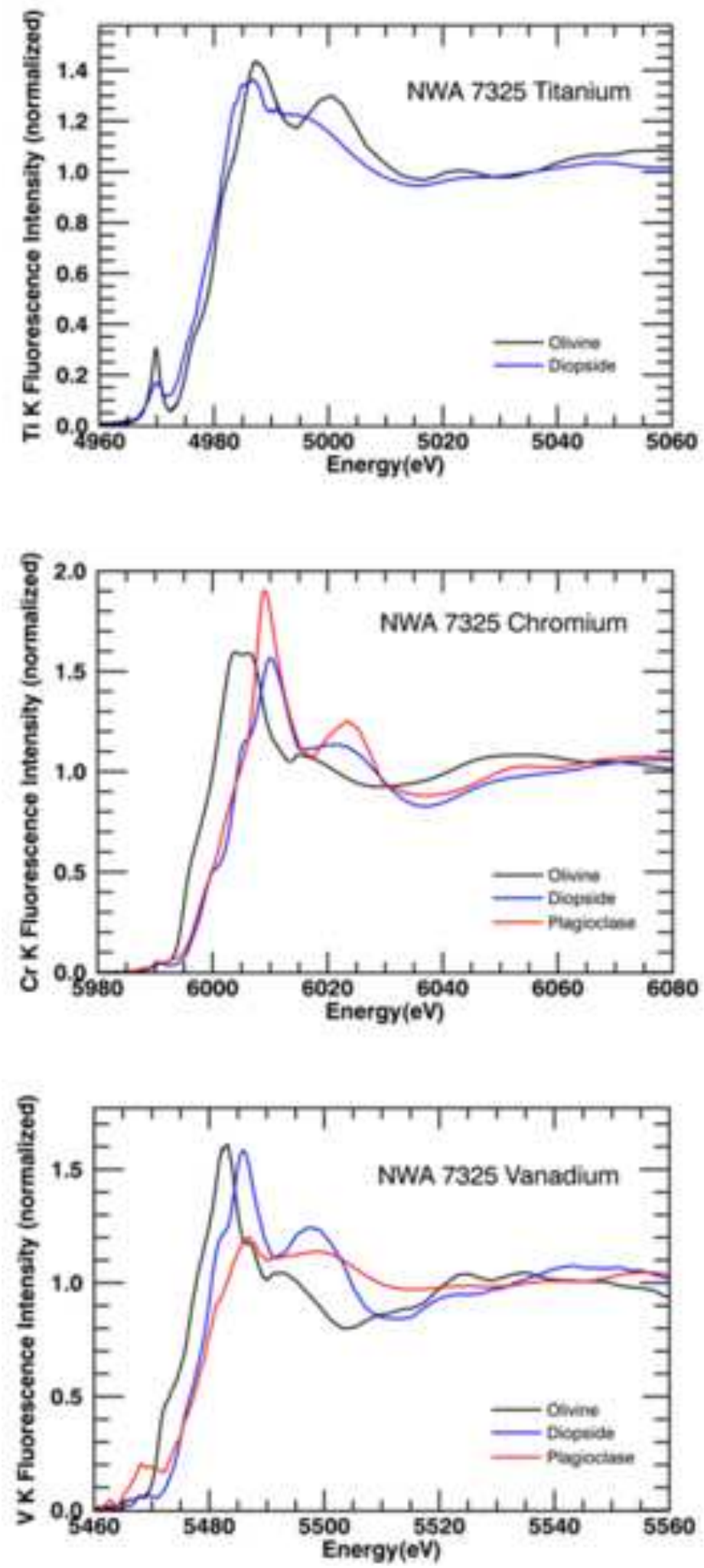

Y-791538
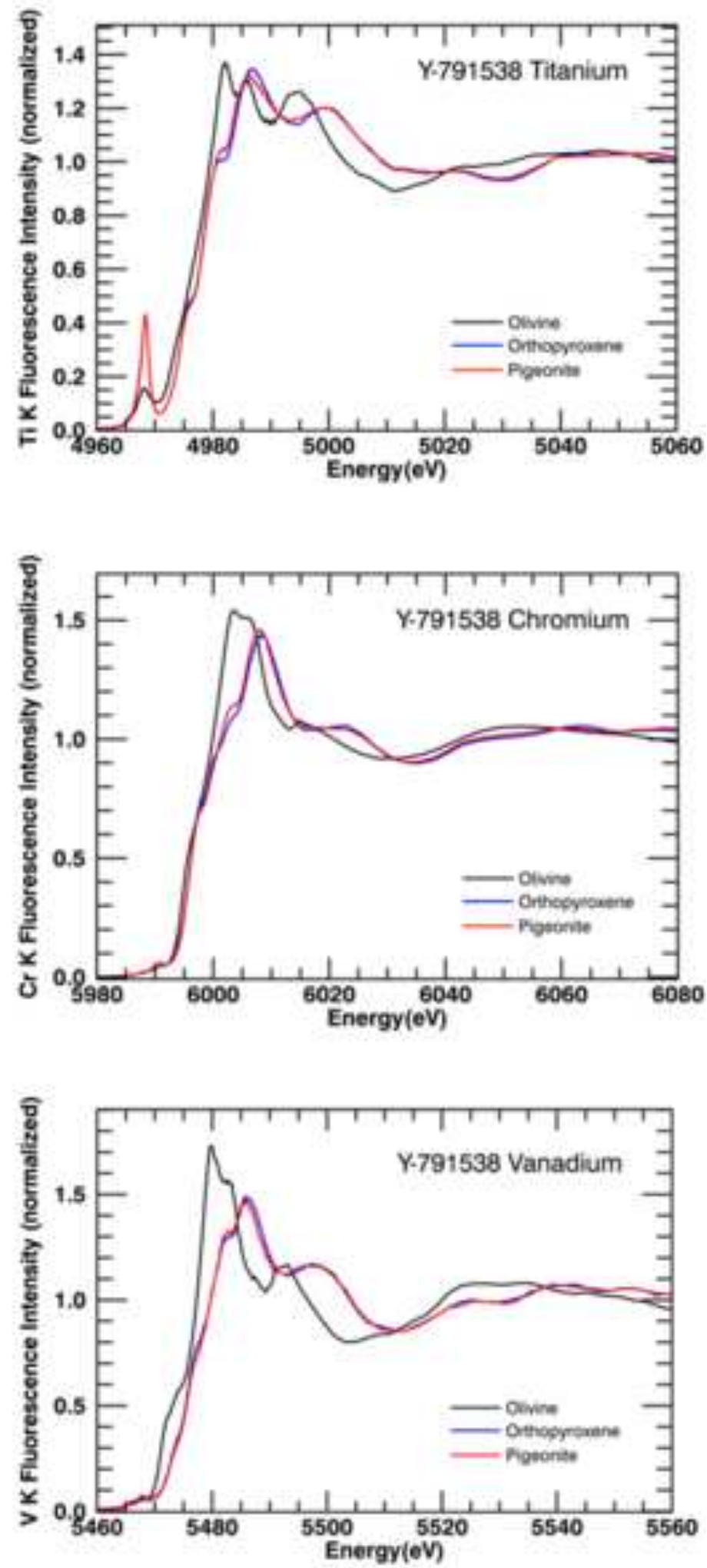


\section{Titanium}

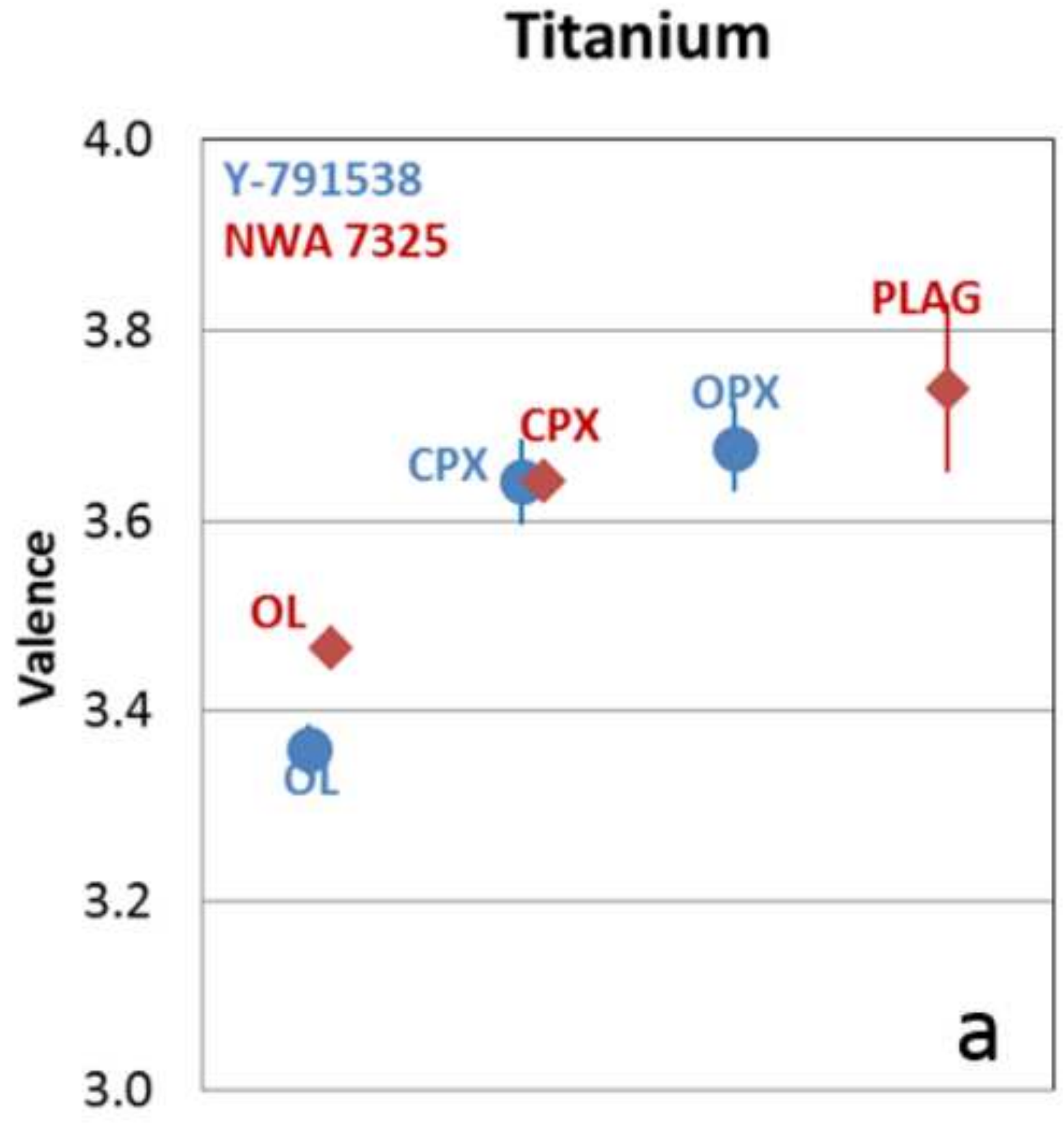

Figure 8a

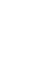

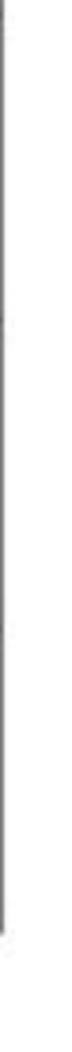
a
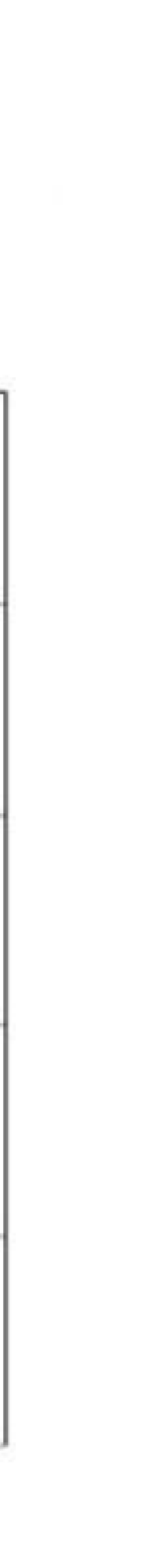

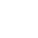

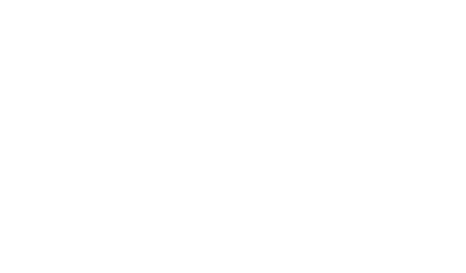




\section{Chromium}

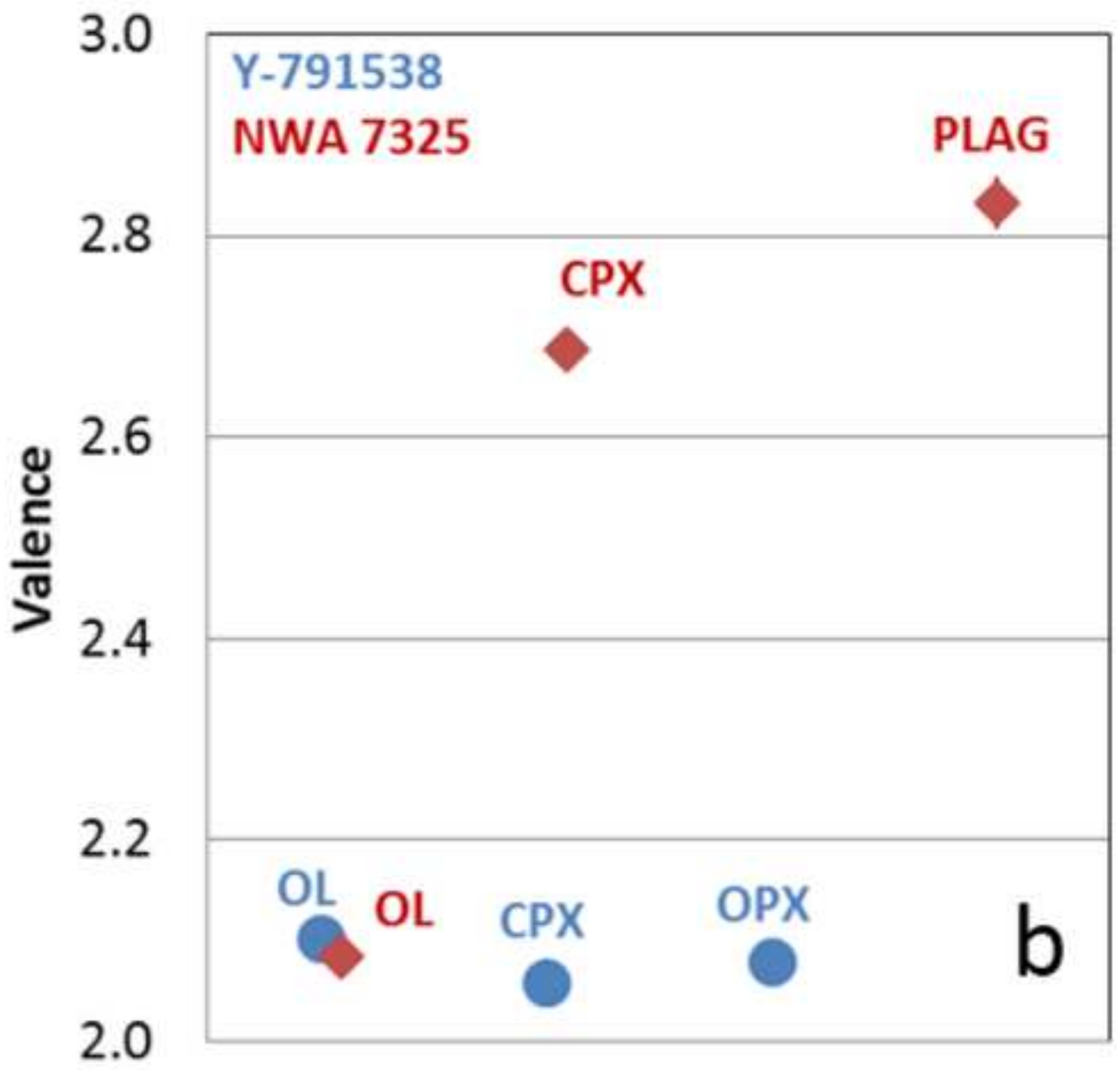




\section{Vanadium}

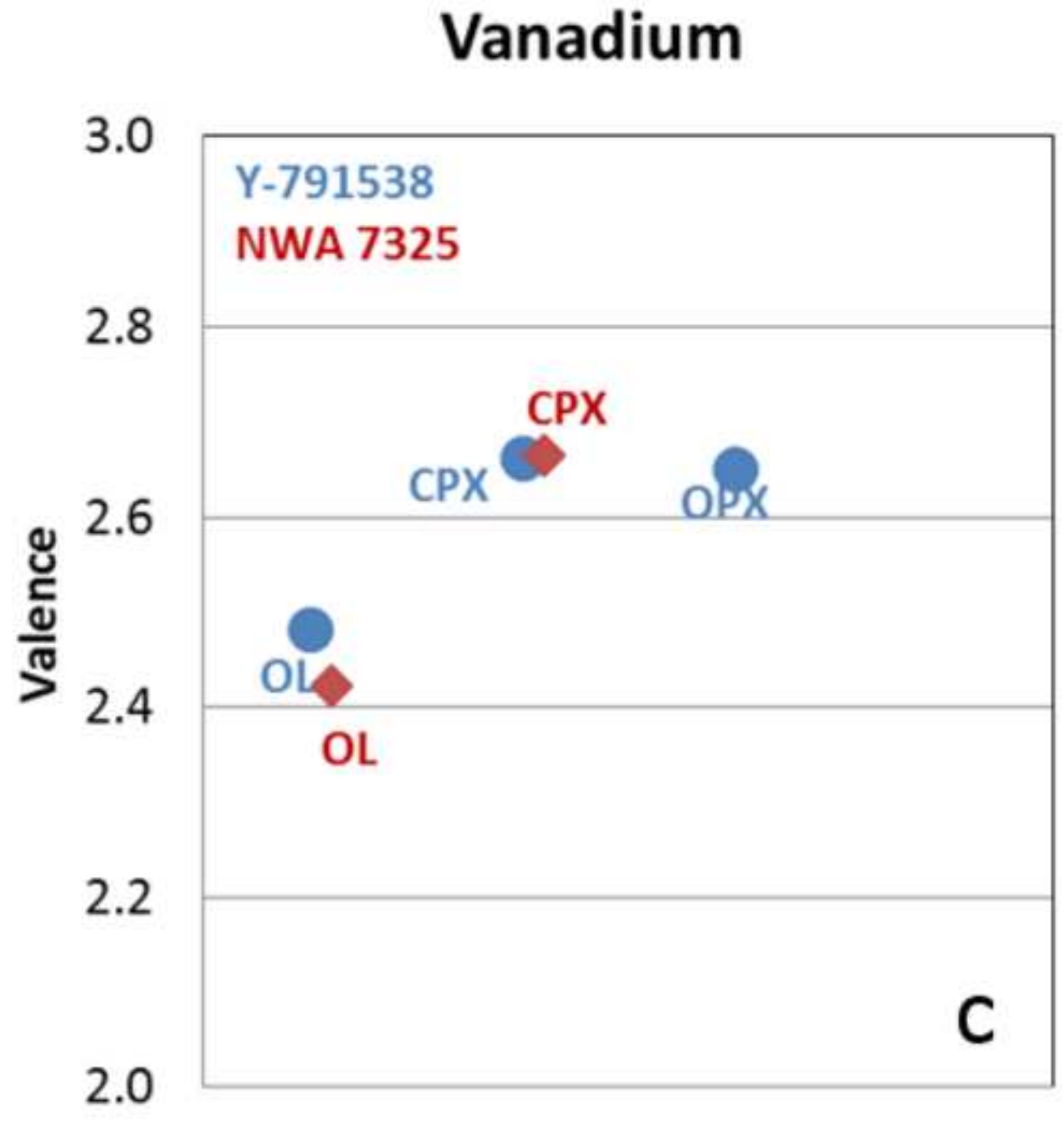

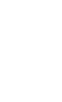

.


Olluine (V)

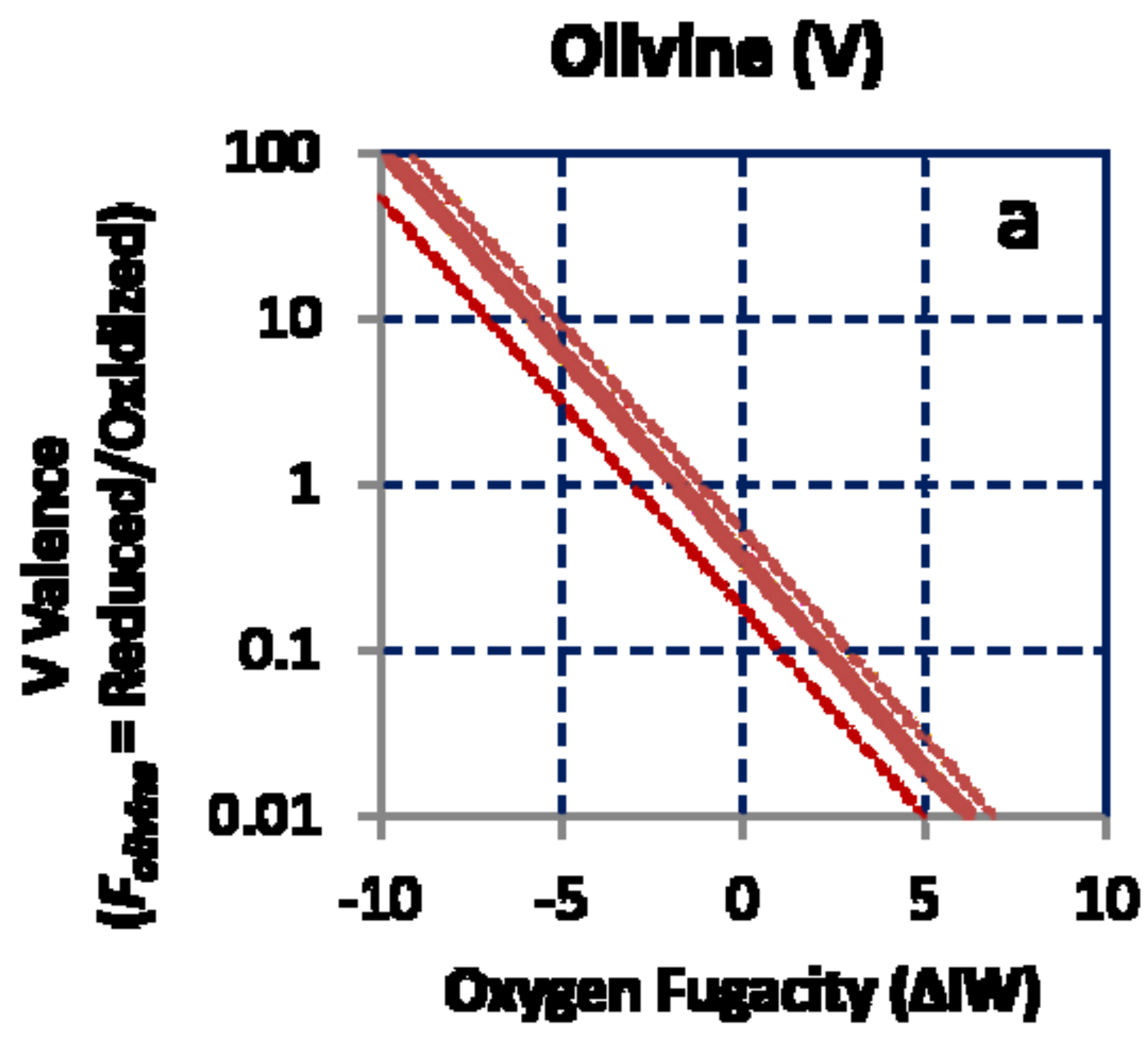

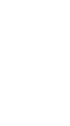

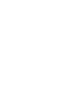

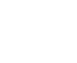

.

$x^{2}$

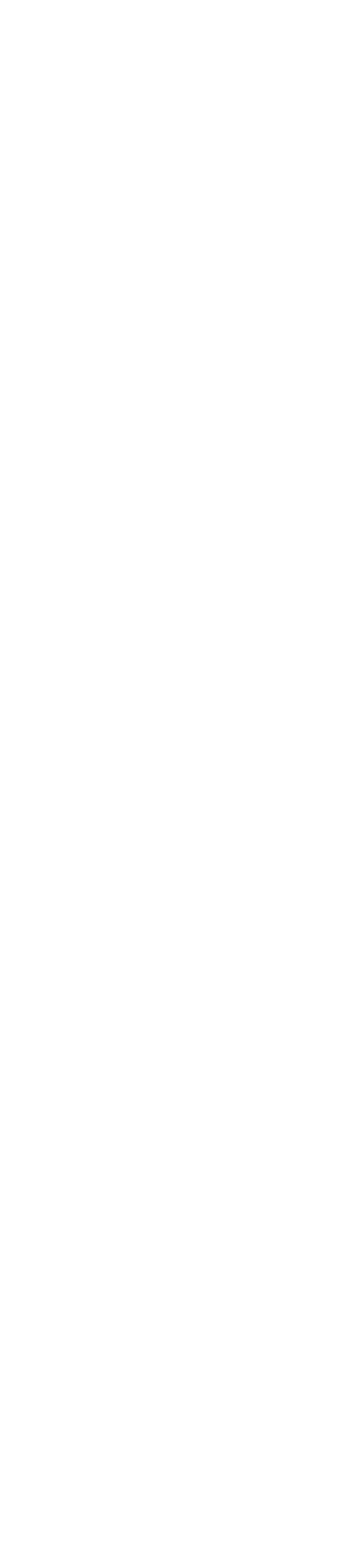

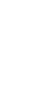

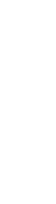
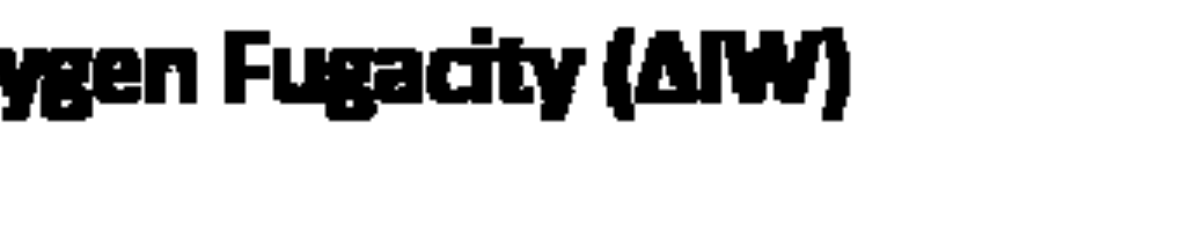


\section{Ollvine (TI)}

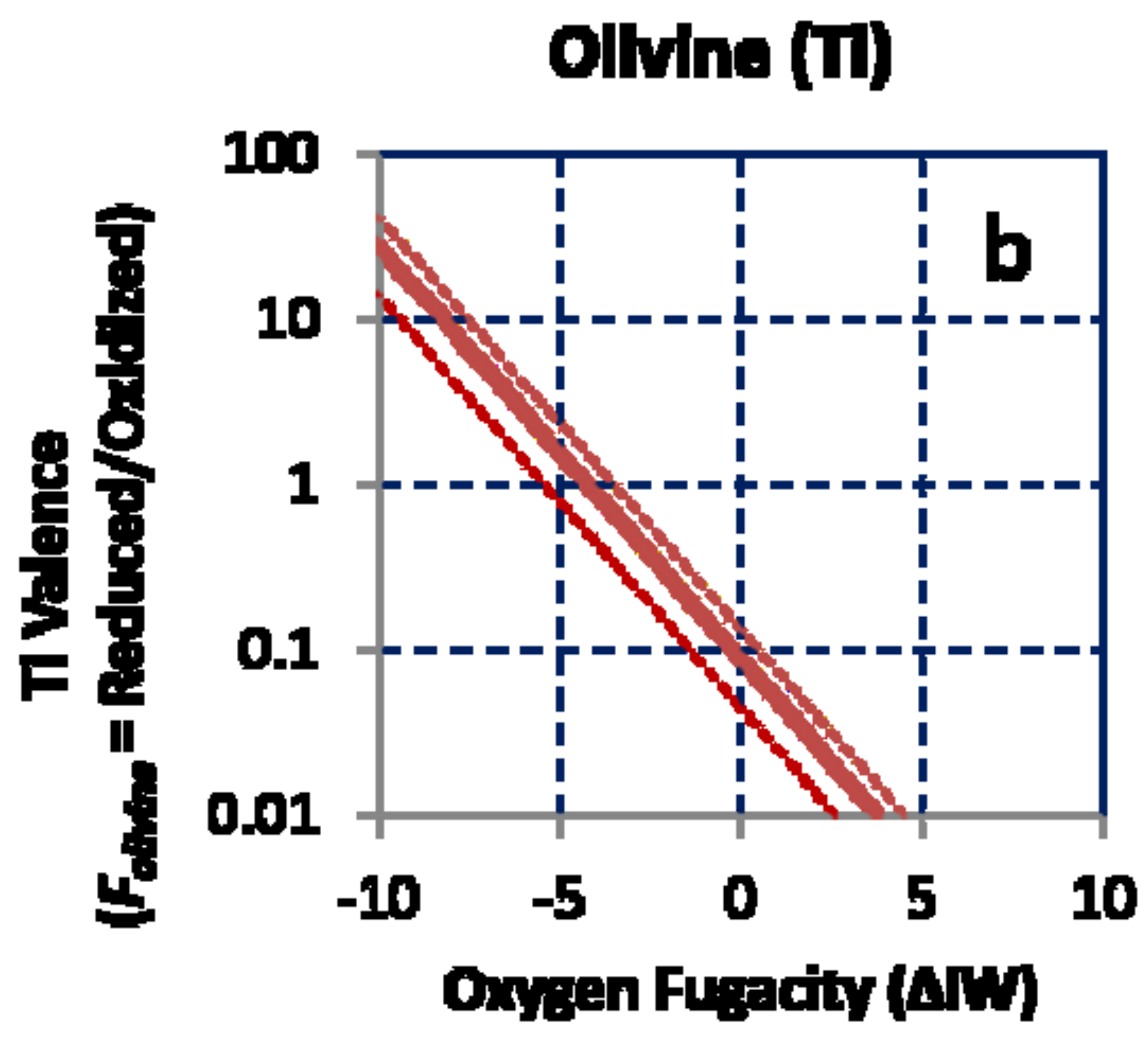




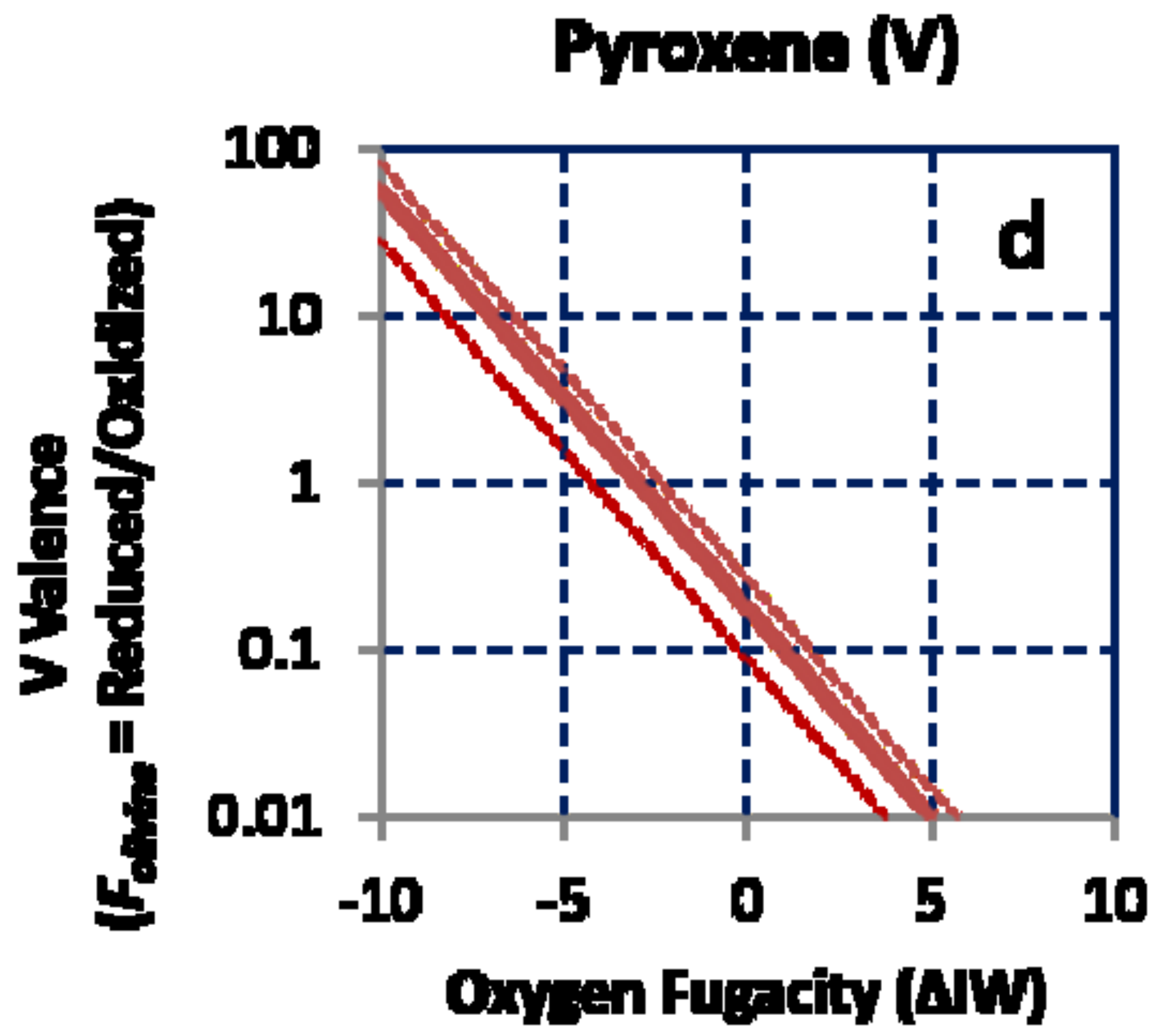


Pyroxene (Ti)

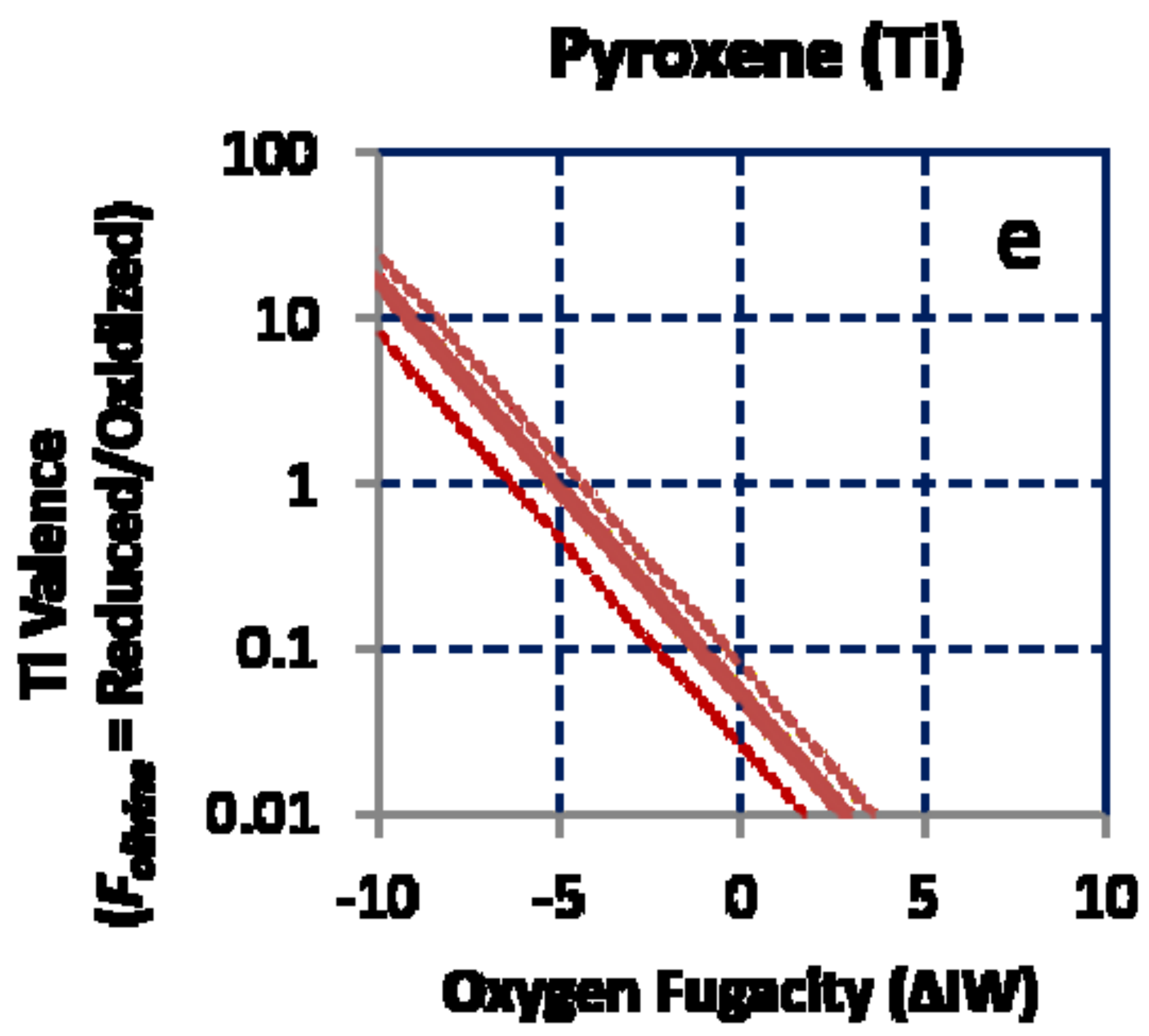




\section{NWA 7325}
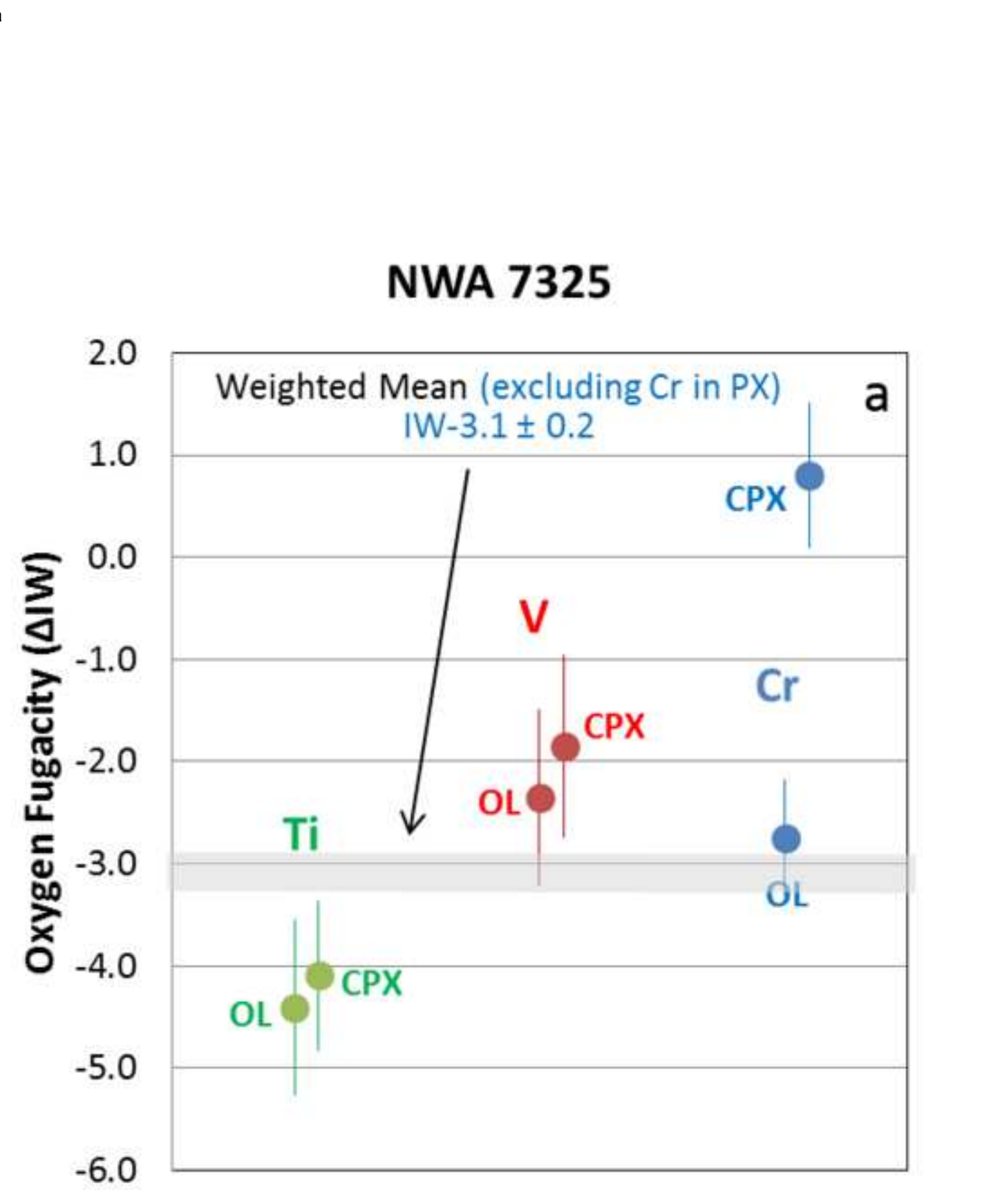


\section{Y-791538}

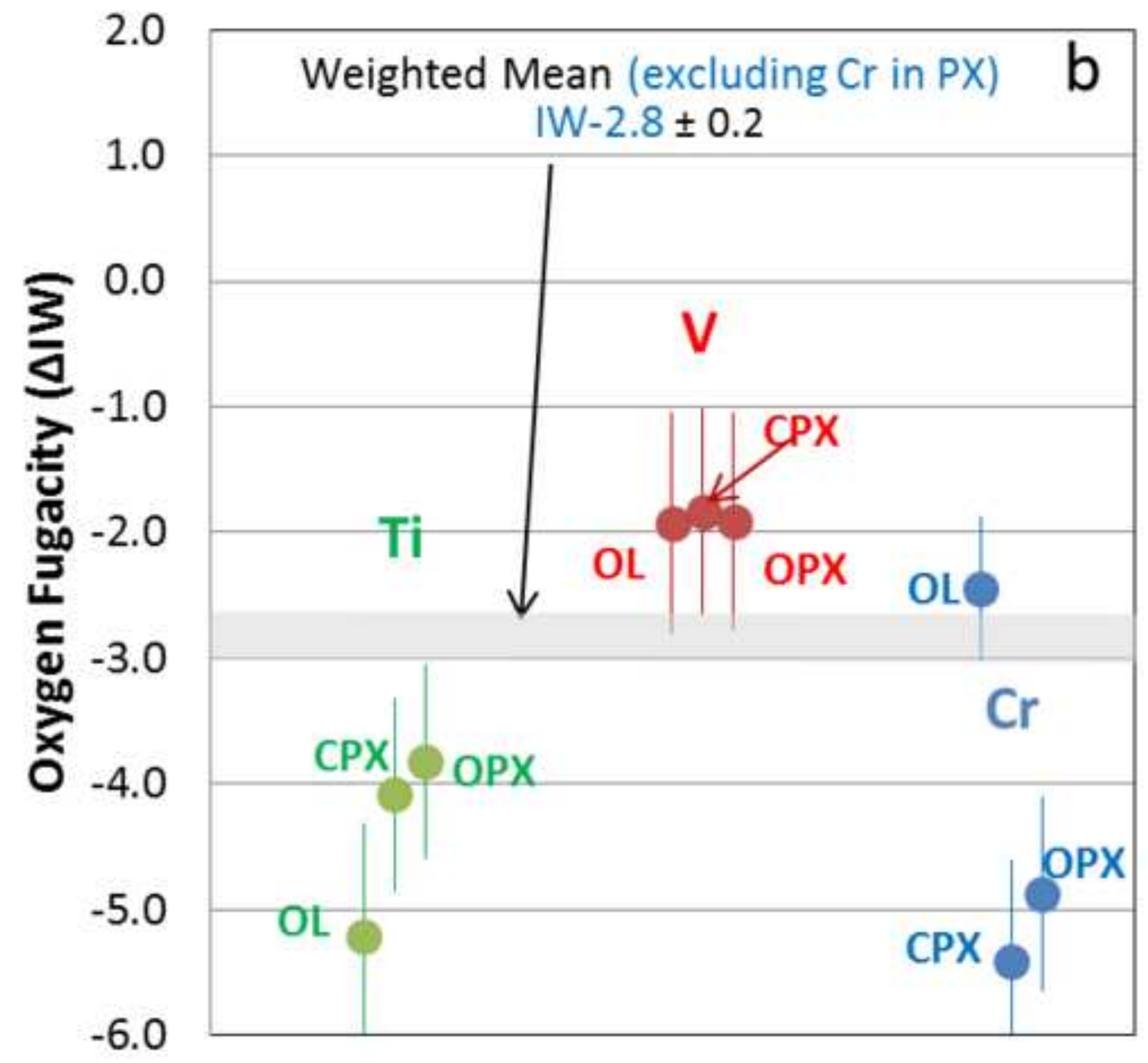

